\title{
Componentes de condução da luz natural em edifícios multifamiliares: análise de um código de obras
}

\author{
Daylight conduction components in apartment buildings: \\ analyses of a building code
}

\section{Guilherme Nóbrega de Castro \\ Solange Maria Leder \\ Luiz Bueno da Silva \\ Erivaldo Lopes de Souza}

\section{Resumo

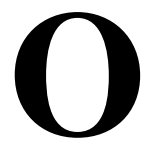

uso da luz natural como fonte de iluminação, além dos impactos positivos no bem-estar físico e mental do homem, possui vantagens econômicas. Estas, contudo, dependem da obtenção do nível de iluminação requerido para a tarefa. Neste estudo, o potencial de aproveitamento da luz natural foi analisado considerando-se as dimensões mínimas de sistemas de iluminação natural permitidas para ambientes residenciais, tendo como critério o Código de Obras da cidade de João Pessoa. Os sistemas de iluminação natural analisados consistem em componentes de passagem com componentes de condução. Simulação computacional feita com o software Daysim foi adotada para analisar o comportamento da luz natural. Realizaram-se 480 simulações para cinco ambientes, associando três variáveis no componente de condução: peitoril transparente e opaco (i), componente de condução saliente e encravado (ii), cinco profundidades (iii) a três variáveis do entorno: máxima ocupação do solo (i), duas alturas de pavimento (ii), quatro orientações (iii). Os parâmetros de análise foram: iluminância natural útil (INU) e autonomia da luz natural (ALN). Com os resultados, percebe-se que os limites mínimos dos critérios do Código não favorecem o aproveitamento da iluminação natural: $40 \%$ dos modelos simulados apresentam iluminação natural insuficiente. Os ambientes iluminados através de janelas altas têm os piores resultados.

Palavras-chaves: Iluminação natural. Simulação computacional. Componentes de condução da luz. Código de edificações.

\begin{abstract}
Aside from the emotional and health benefits, daylight has been shown to have a significant impact on energy efficiency. The saving potential due to daylighting, however, depends on the daylight availability inside the building. In this work the daylighting performance of rooms in a residential building was analyzed. The daylight system consisted of daylight conduction components associated with passthrough components, designed considering the minimum standards set out by the building code of the city of João Pessoa. The Daysim software was adopted to simulate the daylight, 480 simulations were analyzed, including five different rooms (living room; bedroom; maid's room; kitchen and bathroom), three variables of pass-through components (opaque and transparent sill; protruding and enclosed balcony; and balcony's depth), and three variables associated with the surroundings (maximum plot ratio allowed; two stories height; and four facade orientations). Daylight Autonomy (DA) and Useful Daylight Illuminance (UDI) are the performance indicators used to predict the rooms' performance. We concluded that the minimum standards for conduction and pass-through components set out by the building code can not contribute to the efficient use of daylight (approximately 40\% of the simulated models had insufficient daylight), especially when a high window is connected to a pass-through component.
\end{abstract}

Recebido em 10/09/14 Aceito em 25/03/15

Keywords: Daylighting. Computer simulation. Light conduction componentes. Building code.

CASTRO, G. N. de; LEDER, S. M.; SILVA, L. B. da S.; SOUZA, E. L. de. Componentes de condução da luz natural em edifícios multifamiliares: análise de um código de obras. Ambiente Construído, Porto Alegre,v. 15, n. 2, p. 25-45, abr./jun. 2015.

ISSN 1678-8621 Associação Nacional de Tecnologia do Ambiente Construído.

http://dx.doi.org/10.1590/s1678-86212015000200012 


\section{Introdução}

Mais do que uma solução para economia de energia, a iluminação natural é de melhor qualidade, e sua variação contínua resulta em mudanças na luz, como direção, sombra e cor. Essa dinâmica influencia na percepção visual do espaço e objetos e na qualidade ambiental. A luz natural favorece, ainda, o bem-estar, principalmente por sua relação com o ciclo circadiano (LAM, 1986; LESLIE, 2003; SERRA, 1998).

Todo ambiente interno de permanência prolongada necessita de contato com o exterior, possível através das aberturas do edifício. A luz natural pode ser admitida nos ambientes internos através de aberturas para o exterior (laterais ou zenitais) ou através de outro ambiente, como varandas, corredores, galerias, pátios, átrios, poços de luz. Segundo a definição do RTQ-R (BRASIL, 2010, p. 4), abertura é toda área “[...] da envoltória do edifício, aberta ou com fechamento translúcido ou transparente, que permita a entrada da luz e/ou ar [...]".

Apesar da existência de manuais, normas e recomendações para o projeto de aberturas, o Código de Obras continua sendo o principal instrumento regulador do projeto de sistemas de iluminação natural, fato observado por Julian (1998) e Boubekri (2004) em relação às normas dos países por eles analisados, como Alemanha, França, EUA e Inglaterra. No Brasil, o Código de Obras é a "lei municipal que disciplina, dentro dos limites do município, toda e qualquer construção, reforma e ampliação de edificações, bem como sua utilização, visando ao atendimento de padrões de segurança, higiene, salubridade e conforto" (ABNT, 1992b). O padrão comum utilizado nos Códigos de Obras para definição da área mínima de abertura para iluminação é a relação entre a área de janela e de piso, como recomendam Bahia et al. (1997), porém, por não contemplar adequadamente as variáveis que interferem na iluminação natural, essa relação é limitada quanto ao conforto ambiental e à economia de energia (AMARAL; PEREIRA, 1999; FERNANDES, 2009). Na Tabela 1 são apresentados diferentes padrões e recomendações/exigências presentes nos Códigos de Obras de capitais brasileiras das ZB1 e ZB8 do Zoneamento Bioclimático Brasileiro (ABNT, 2005c). Mesmo com os climas distintos dos locais selecionados, as recomendações/exigências são muito semelhantes.

Tabela 1 - Padrões adotados nos Código de Obras de algumas cidades brasileiras

\begin{tabular}{|c|c|c|}
\hline CIDADE/ZB & PADRÕES & RECOMENDAÇÕES/EXIGÊNCIAS \\
\hline $\begin{array}{c}\text { Curitiba (PR) } \\
\text { ZB1 }\end{array}$ & $\begin{array}{l}\text { 1. Área de janela/área de } \\
\text { piso; } 2 \text {. Profundidade } \\
\text { máxima do ambiente. }\end{array}$ & $\begin{array}{l}\text { 1. 1/6 para sala e quarto, e } 1 / 8 \text { para cozinha e banheiro. } \\
\text { 1/8 para sala, cozinha e banheiro e } 1 / 6 \text { para quarto em } \\
\text { habitação popular. "Tolerada" abertura zenital no } \\
\text { banheiro; } 2.3 x \text { Pé-direito. }\end{array}$ \\
\hline $\begin{array}{c}\text { João Pessoa } \\
\text { (PB) ZB8 }\end{array}$ & $\begin{array}{l}\text { 1. Área de janela/área de } \\
\text { piso; } 2 \text {. Profundidade } \\
\text { máxima do ambiente. }\end{array}$ & $\begin{array}{c}\text { 1. 1/6 para sala e quarto, e } 1 / 10 \text { para cozinha e banheiro. } \\
1 / 4 \text { e } 1 / 8 \text { respectivamente, quando houver espaço } \\
\text { intermediário (distância máxima de } 2,50 \mathrm{~m} \text { para o } \\
\text { exterior); } 2.3 \mathrm{x} \text { Pé-direito. }\end{array}$ \\
\hline $\begin{array}{l}\text { Maceió (AL) } \\
\text { ZB8 }\end{array}$ & Não especificado. & $\begin{array}{l}\text { O atendimento aos níveis de iluminação é de } \\
\text { competência e responsabilidade do projetista. }\end{array}$ \\
\hline $\begin{array}{c}\text { Natal (RN) } \\
\text { ZB8 }\end{array}$ & $\begin{array}{l}\text { 1. Área de janela/área de } \\
\text { piso; } 2 \text {. Profundidade } \\
\text { máxima do ambiente. }\end{array}$ & $\begin{array}{l}\text { 1. 1/6 para sala e quarto, e } 1 / 8 \text { para cozinha e banheiro. } \\
\text { Pode haver iluminação zenital de } 6 \% \text { na cozinha e no } \\
\text { banheiro; } \\
\text { 2. 3x Pé-direito. Não menciona espaço intermediário. }\end{array}$ \\
\hline $\begin{array}{l}\text { Porto Velho } \\
\text { (RO) ZB8 }\end{array}$ & $\begin{array}{l}\text { 1. Área de janela/área de } \\
\text { piso; } 2 \text {. Profundidade } \\
\text { máxima do ambiente; } 3 \text {. } \\
\text { Área mínima de abertura. }\end{array}$ & $\begin{array}{l}\text { 1. 1/5 para todos os ambientes. Quando houver espaço } \\
\text { intermediário, deve-se acrescentar } 25 \% \text { da área do piso; } \\
\text { 2. } 2,5 x \text { Pé-direito ou 2x Largura da abertura; } 3.0,60 \mathrm{~m}^{2} \text {. }\end{array}$ \\
\hline $\begin{array}{c}\text { Recife }(\mathrm{PE}) \\
\text { ZB8 }\end{array}$ & $\begin{array}{l}\text { 1. Área de janela/área de } \\
\text { piso; } 2 \text {. Profundidade } \\
\text { máxima do ambiente. }\end{array}$ & $\begin{array}{c}\text { 1. } 1 / 6 \text { para sala e quarto, } 1 / 8 \text { para cozinha, e } 1 / 10 \text { para } \\
\text { banheiro. Pode haver espaço intermediário (distância } \\
\text { máxima de } 2,00 \text { m para o exterior); } 2.2,5 x \text { Largura do } \\
\text { ambiente. }\end{array}$ \\
\hline
\end{tabular}

Fontes: Curitiba (2007), João Pessoa (1971), Maceió (2007), Natal (2004), Porto Velho (1973) e Recife (1997). 
No Código de Obras de João Pessoa, local de aplicação desta investigação, o dimensionamento exigido para as aberturas é dado apenas pela relação entre as áreas de janela e de piso. Para os ambientes de uso prolongado - sala, quarto, copa, cozinha, gabinete de trabalho - é exigido $1 / 6$ da área do piso, e para os ambientes de utilização eventual - sanitário, garagem, hall, despensa, circulações horizontal e vertical -, 1/10 da área de piso. É possível aberturas através de outros ambientes, como varanda e área de serviço, desde que a distância máxima da abertura para a face exterior da edificação seja de 2,50 m, observando a relação de 1/4 e 1/8 da área do piso para ambiente de uso prolongado e eventual respectivamente. Admite-se ainda - desde que respeitada a distância máxima para o exterior de $2,50 \mathrm{~m}$ - a iluminação de um banheiro através de outro banheiro da mesma unidade habitacional.

Este estudo verifica o desempenho lumínico de sistemas de iluminação natural que agregam componentes de passagem e condução da luz natural, concebidos a partir das recomendações do Código de Obras. Os parâmetros de análise foram os níveis de iluminação e a distribuição destes. Nesse contexto, são apresentadas a seguir algumas considerações sobre os sistemas de iluminação natural e os parâmetros de análise utilizados nesta pesquisa.

\section{Admissão e sistema de iluminação natural}

Conforme a classificação de Baker, Fachiotti e Steemers (1993), existem dois grupos principais de elementos nos sistemas de iluminação natural: componentes de condução da luz natural e componentes de passagem da luz natural. Essa mesma classificação é adotada pela NBR 15215-1 (ABNT, 2005a). Os componentes de condução da luz natural são espaços construídos que guiam e/ou distribuem a luz natural para o interior da edificação, e os componentes de passagem da luz natural, as aberturas propriamente ditas, em material transparente ou translúcido, que permitem a penetração da iluminação exterior para o interior e/ou de um espaço para outro. A combinação desses componentes compõe o sistema de iluminação natural dos edifícios (SERRA, 1998).

As principais variáveis da abertura que influenciam a iluminação natural de um ambiente interno são: dimensão, forma e localização na parede. A dimensão da abertura teve maior influência nos níveis de iluminação natural no estudo de Bittencourt et al. (1995), na cidade de Maceió, enquanto a forma e a localização da abertura influenciaram na distribuição do fluxo luminoso. Aberturas horizontais apresentam distribuição mais uniforme, principalmente se estiverem localizadas mais próximas ao teto. A iluminação interna, tanto quantitativa quanto qualitativamente, é uma função não apenas do tamanho, formato e colocação das janelas, mas também das propriedades reflexivas das superfícies interiores (HOPKINSON; PETHERBRIDGE; LONGMORE, 1975).

A admissão da iluminação natural através de aberturas laterais pode ser dificultada devido às obstruções externas do entorno e/ou à geometria do próprio edifício, que podem bloquear o sol. Essas obstruções podem ser positivas quando se potencializa o aproveitamento da luz natural por meio de reflexões e há necessidade de sombreamento das aberturas (CAPELUTO, 2002; FROTA; SCHIFFER, 2001).

Segundo Boyce (1998), a iluminação natural pode proporcionar bom desempenho visual, boa reprodução de cores e visualização de detalhes, porém pode também propiciar ofuscamento e reflexos indesejáveis. Pereira (1995) descreve que ambientes iluminados lateralmente apresentam direção da luz natural predominantemente de cima para baixo e distribuição da iluminação interna não uniforme - áreas próximas à janela são mais iluminadas, frequentemente de forma excessiva, e áreas mais afastadas ficam mais escuras.

Quanto à profundidade (P) de um ambiente iluminado por uma abertura lateral, para a Chartered Institution of Building Services Engineers (THE CHARTERED..., 1987), a profundidade do ambiente deve ser 2 a 2,5 vezes a altura da janela, para que haja suficiente iluminação natural no ambiente. Ou, mais precisamente, em função dos valores de largura $(\mathrm{L})$, altura $(\mathrm{H})$ e refletância da parede de fundo $\left(\mathrm{R}_{\mathrm{f}}\right)$, se a seguinte expressão for respeitada: $[(\mathrm{P} / \mathrm{L})+(\mathrm{P} / \mathrm{H})] \leq\left(2 / 1-\mathrm{R}_{\mathrm{f}}\right)$. Já Bahia et al. (1997) afirmam que a dimensão máxima de profundidade de um ambiente interno possível de ser iluminada naturalmente para os compartimentos de permanência prolongada das edificações residenciais corresponde a 2,5 vezes a altura do ponto mais alto do vão de iluminação do compartimento.

Reinhart (2005) observou que a profundidade do ambiente iluminada naturalmente é em torno de 1 a 2 vezes a altura do piso à verga da abertura, ao analisar escritórios iluminados por abertura lateral com persianas, através de simulação computacional (ou simulação dinâmica da luz natural) de algumas cidades dos Estados Unidos e do Canadá com diferentes climas. Contudo, a precisão dessa regra depende de muitas variáveis, 
principalmente da transparência do vidro e do nível de iluminação desejado, bem como o percentual mínimo do ano a ser iluminado naturalmente, estabelecido como meta. Por exemplo, a uma distância horizontal em torno de $0,75,1,5$ e 2 vezes a altura do piso à verga da abertura, a autonomia da luz natural (ALN) é de, respectivamente, $75 \%, 50 \%$ e $25 \%$.

Os principais exemplos de ambientes através dos quais a luz natural é guiada e/ou distribuída (componente de condução) são pátios, galerias, varandas, jardins de inverno e pérgulas. No Brasil, algumas soluções são aceitas pelas legislações municipais, como a cozinha ou o banheiro iluminados através da área de serviço e, em alguns casos, um banheiro iluminado através de outro banheiro. Os componentes de condução, geralmente, apresentam altura de um ou dois pavimentos, profundidade entre $1,00 \mathrm{~m} \mathrm{e} 5,00 \mathrm{~m}$, e localizam-se no perímetro do edifício, servindo de filtro entre as condições externas e internas, protegendo o ambiente interno da radiação direta do sol e da chuva, e direcionando e distribuindo a iluminação natural do exterior para o interior. Nos edifícios multifamiliares brasileiros, a utilização de varandas é justificada mais pela intenção de criação de um espaço intermediário do que pela proteção dos espaços interiores. As varandas são classificadas em função de algumas características, tais como a distribuição em planta, em fachada, e a geometria. Em relação ao "encaixe" no volume do edifício, podem ser consideradas como encravadas, semiencravadas ou salientes, como esquematizado na Figura 1 (MARAGNO, 2010; MASCARÓ, 2004; SERRA, 1998).

A variável que mais influencia no bloqueio da radiação solar através da varanda é a relação altura versus profundidade: quanto mais profunda, encravada, extensa em relação à fachada e dotada de mais apoios, maior será sua eficiência no bloqueio das radiações solares (MARAGNO, 2010). Porém, Bahia et al. (1997) consideram que, para iluminação natural, a profundidade das varandas não pode ser maior do que $2,00 \mathrm{~m}$. No estudo realizado por Albuquerque e Amorim (2012), considerando um grupo de cidades brasileiras, verificou-se uma diferença de aproximadamente $30 \%$ no alcance da iluminação natural entre um ambiente com abertura sem proteção solar e um ambiente com varanda contígua de $1,50 \mathrm{~m}$ de profundidade.

\section{Parâmetros de análise da iluminação natural}

Os principais parâmetros de análise da eficiência da luz natural aplicados em estudos recentes são as medidas dinâmicas de autonomia da luz do natural (ALN, Daylight Autonomy - DA) e iluminância natural útil (INU, Useful Daylight Illuminance UDI). Para a geração desses parâmetros, são necessários dados da luz natural ou radiação solar ao longo do ano e em intervalos de $1 \mathrm{~h}$. Em comparação com as medidas estáticas, as medidas dinâmicas têm a vantagem de considerar a quantidade e a natureza das variações diárias e sazonais da iluminação natural (ALBUQUERQUE; AMORIM, 2012).

A ALN corresponde à porcentagem de horas (do ambiente ocupado) em que a iluminância no plano de trabalho atinge um valor estipulado como padrão para as atividades do ambiente, possibilitando autonomia da iluminação natural em relação à luz artificial. Essa medida, entretanto, não contabiliza os valores inferiores ao estipulado (MARDALJEVIC; REINHART; ROGERS, 2006). Como apontam Matos et al. (2007), para uma análise a partir dos valores de ALN, maiores valores não significam a garantia de economia de energia, pois, para avaliação da ALN, o sistema de iluminação artificial e o tipo de controle não são levados em consideração. Esse parâmetro não permite a identificação das situações em há níveis de iluminação excessivos, que podem provocar desconforto visual e/ou térmico.

Figura 1 - Tipo de varanda conforme o encaixe no edifício
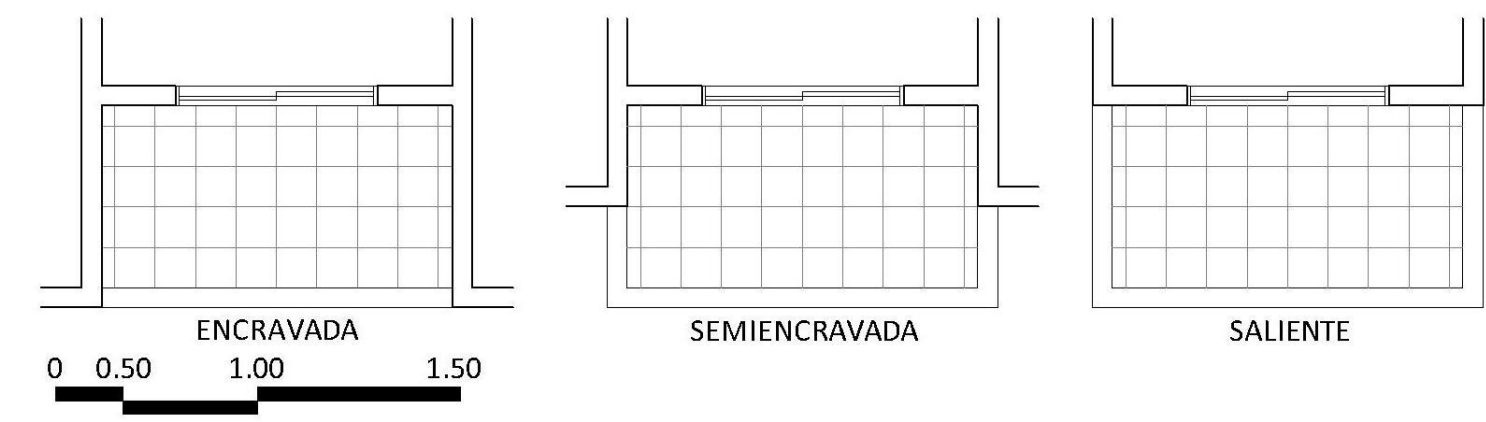

SALIENTE

Fonte: baseado em Mascaró (2004). 
A INU, que surgiu como alternativa à ALN, corresponde à porcentagem de horas, em 1 ano, em que a iluminância no plano de trabalho atinge valores dentro do intervalo de aproveitamento da luz natural; para o uso residencial, o intervalo é de 100 a 3.000 lux. Esse intervalo deve-se às seguintes considerações: o limite inferior, de 100 lux, possibilita a iluminação de tarefas de baixa complexidade ou, ainda, complementação com luz artificial, enquanto os níveis acima de 3.000 lux devem ser evitados, pois podem gerar desconforto visual e/ou térmico (MARDALJEVIC et al., 2011, 2012). Reinhart e Weissman (2012) comentam que esse parâmetro de análise não se restringe apenas à luz natural, pois visa combinar a disponibilidade da luz, o conforto visual e as preocupações energéticas.

\section{Metodologia}

As etapas descritas a seguir compreendem a metodologia adotada.

\section{Caracterização dos modelos de análise}

Este estudo teve como base um conjunto de modelos de ambientes de uso residencial, definidos segundo o critério de dimensões mínimas - área, largura e altura - exigidas pelo Código de Obras de João Pessoa. A profundidade dos ambientes foi definida a partir das medidas de área e largura, sendo a área da abertura definida em função da área de piso. De acordo com o Código de Obras, uma unidade residencial necessita de, pelo menos, uma sala, um quarto, uma cozinha e um banheiro. As exigências para salas e quartos são área de 8,00 $\mathrm{m}^{2}$, largura e altura de $2,60 \mathrm{~m}$. É possível a existência de quartos de $6,00 \mathrm{~m}^{2}$, com largura de $2,20 \mathrm{~m}$ e altura de $2,60 \mathrm{~m}$, e quartos de empregados de $5,00 \mathrm{~m}^{2}$, com largura de $2,00 \mathrm{~m} \mathrm{e}$ altura de 2,40 m. Cozinhas mínimas têm 4,00 $\mathrm{m}^{2}$ de área, largura de $1,60 \mathrm{~m}$ e altura de 2,60 m. Banheiros mínimos têm área de $3,00 \mathrm{~m}^{2}$ e largura de $1,30 \mathrm{~m}$. A única referência à varanda é a possibilidade de abertura de ambientes para esse espaço, respeitando-se a distância máxima de 2,50 $\mathrm{m}$ entre as faces externas dos ambientes e das varandas. A largura mínima das circulações das áreas comuns é de 1,20 m; caso a circulação tenha comprimento maior que $15,00 \mathrm{~m}$, é exigida largura de 1,50 m; a altura mínima da circulação é 2,30 m.

As áreas de abertura foram definidas de acordo com a fenestração mínima exigida pelo Código de Obras para um ambiente iluminado através de um componente de condução da luz: $1 / 4$ da área de piso para salas, quartos e cozinhas, e 1/8 para banheiros. A abertura única de cada ambiente está centralizada na parede da largura. A abertura da sala para a varanda, devido à necessidade e/ou à possibilidade de acesso a este ambiente, é uma porta de 2,10 $\mathrm{m}$ de altura. A abertura do quarto para a varanda é uma janela baixa de $1,10 \mathrm{~m}$ de altura e peitoril de 1,00 m. Já as aberturas para circulações necessitam de peitoril elevado, para resguardar a privacidade da área interna; dessa forma, as janelas do quarto de empregados e da cozinha apresentam altura de $0,63 \mathrm{~m}$ e peitoril de 1,77 m; a janela do banheiro tem peitoril de $1,80 \mathrm{~m}$ e altura de $0,60 \mathrm{~m}$. A Tabela 2 apresenta as características desses modelos.

Foram definidos cinco modelos de varanda/circulação em relação à profundidade: $1,20 \mathrm{~m}, 1,50 \mathrm{~m}, 2,00 \mathrm{~m}, 2,50 \mathrm{~m}$ e $3,00 \mathrm{~m}$. As larguras dos componentes de condução são definidas de acordo com as larguras dos ambientes ao quais eles servem. Quanto à posição desses componentes de condução em relação ao volume edificado, são definidas duas variações: encravada e saliente. Foram simulados peitoris opacos e transparentes na varanda da sala.

A malha de sensores para avaliação da iluminação dos ambientes foi definida de acordo com a NBR 15215-4 (ABNT, 2005b). A sala e os quartos têm o plano de trabalho na altura de uma mesa, $0,75 \mathrm{~m}$; na cozinha e no banheiro, foi definida a altura usual das bancadas das áreas molhadas, 0,90 m. A recomendação de afastamento de malha de pontos de avaliação de no mínimo $0,50 \mathrm{~m}$ das paredes não foi considerada, por se tratar de ambientes com dimensões pequenas; assim, os pontos estão afastados 0,25 m. As Figuras 2 a 6 apresentam plantas baixas e cortes dos ambientes analisados, com a malha de sensores.

Tabela 2 - Características dos modelos

\begin{tabular}{c|c|c}
\hline AMBIENTE-COMPONENTE DE & DIMENSÕES DO & DIMENSÕES DA \\
CONDUÇÃO & AMBIENTE & ABERTURA \\
\hline Sala-Varanda & $2,60 \times 3,08=8,00 \mathrm{~m}^{2}$ & $0,96 \times 2,10=2,01 \mathrm{~m}^{2}$ \\
Quarto-Varanda & $2,20 \times 2,73=6,00 \mathrm{~m}^{2}$ & $1,37 \times 1,10=1,50 \mathrm{~m}^{2}$ \\
Quarto de empregados-Circulação & $2,00 \times 2,50=5,00 \mathrm{~m}^{2}$ & $2,00 \times 0,63=1,26 \mathrm{~m}^{2}$ \\
Cozinha-Circulação & $1,60 \times 2,50=4,00 \mathrm{~m}^{2}$ & $1,60 \times 0,63=1,00 \mathrm{~m}^{2}$ \\
Banheiro-Circulação & $1,30 \times 2,31=3,00 \mathrm{~m}^{2}$ & $0,63 \times 0,60=0,37 \mathrm{~m}^{2}$ \\
\hline
\end{tabular}


Figura 2 - Planta baixa e corte esquemáticos da sala

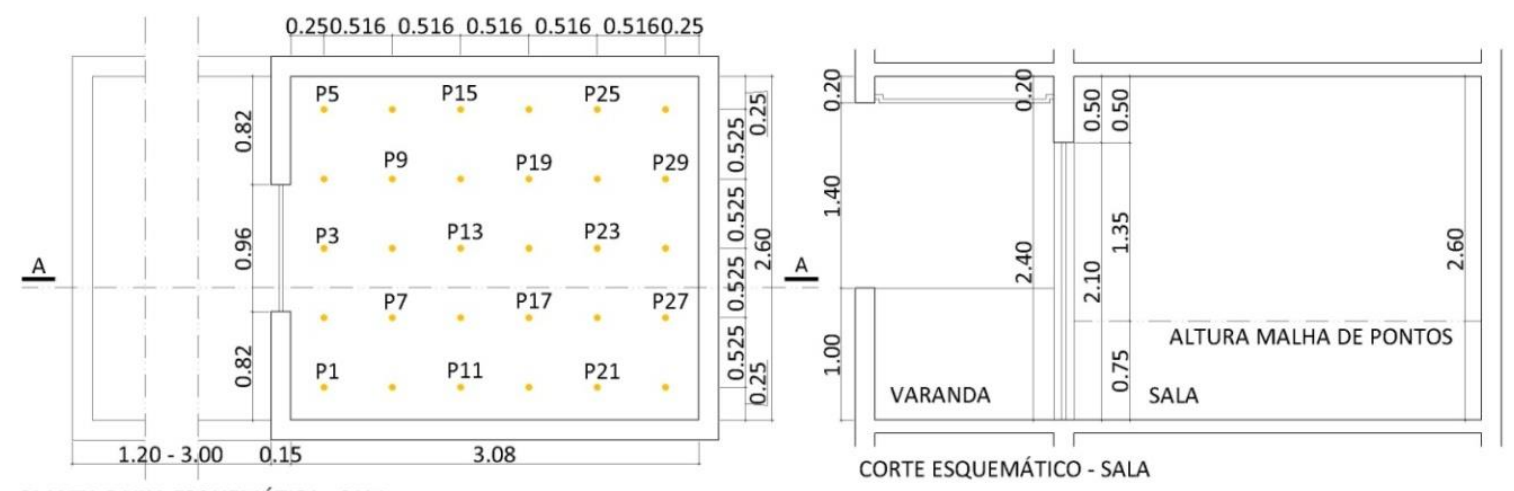

PLANTA BAIXA ESQUEMÁTICA - SALA

Figura 3 - Planta baixa e corte esquemáticos do quarto

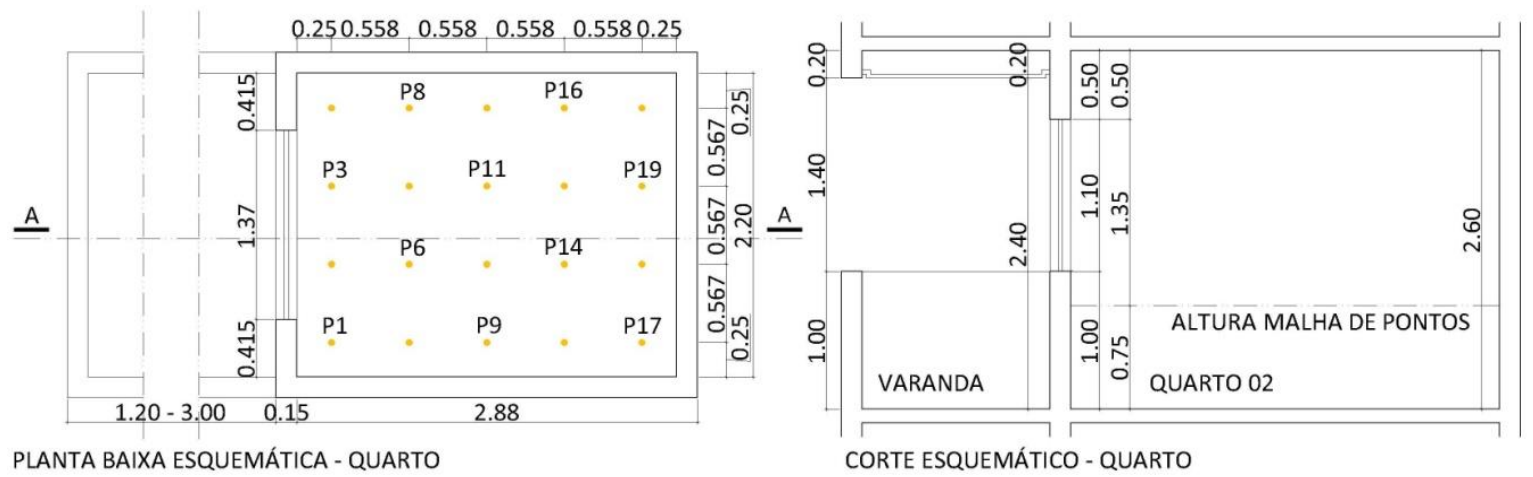

Figura 4 - Planta baixa e corte esquemáticos do quarto de empregados

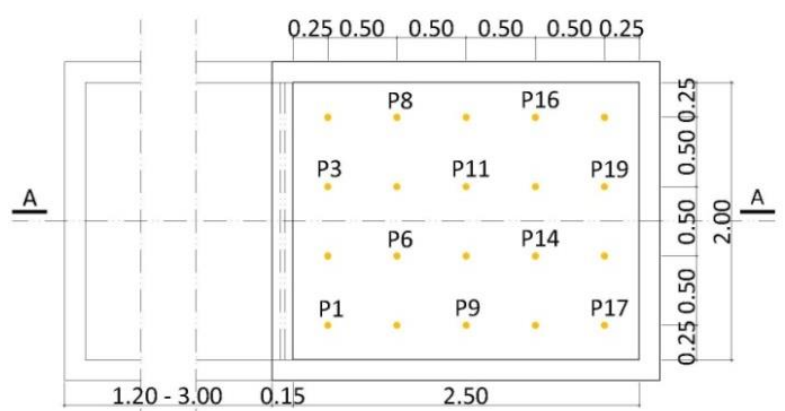

PLANTA BAIXA ESQUEMÁTICA - QUARTO EMPREGADOS

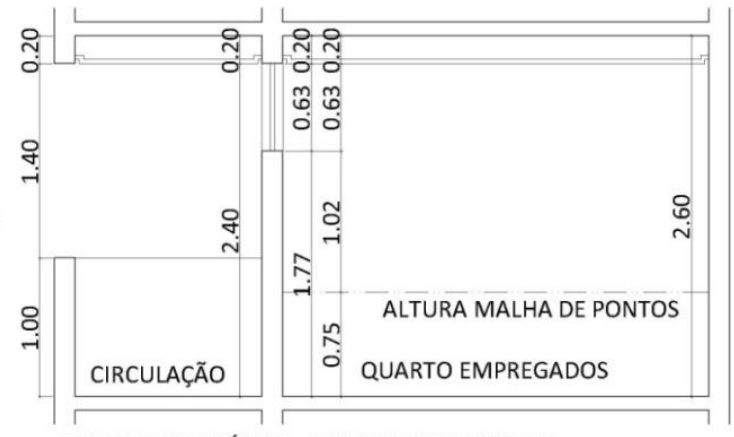

CORTE ESQUEMÁTICO - QUARTO EMPREGADOS

Figura 5 - Planta baixa e corte esquemáticos da cozinha

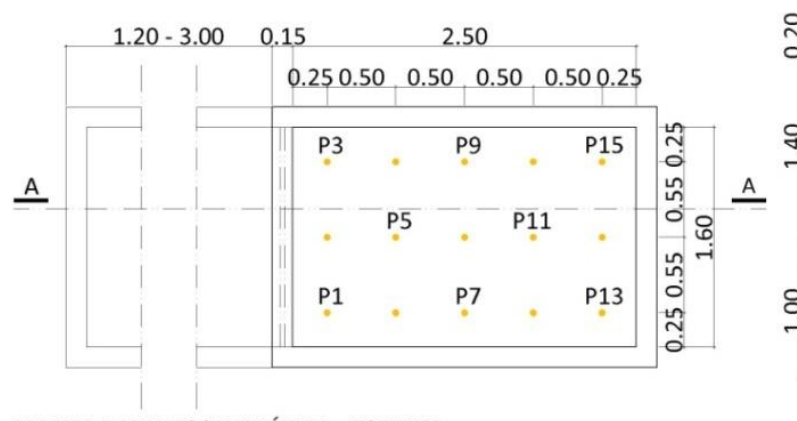

PLANTA BAIXA ESQUEMÁTICA - COZINHA

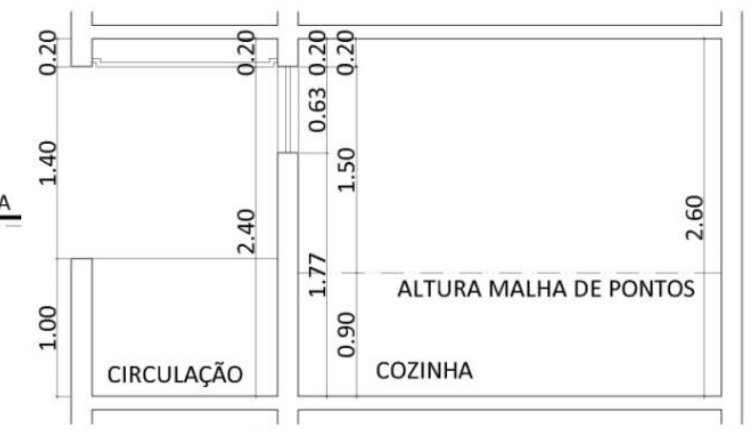

CORTE ESQUEMÁTICO - COZINHA 
Figura 6 - Planta baixa e corte esquemáticos do banheiro

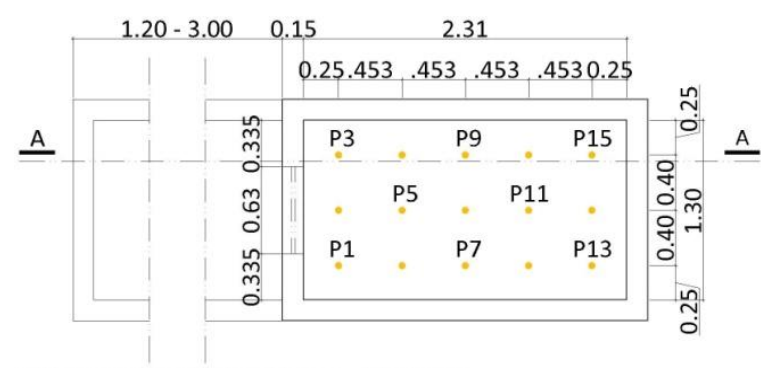

PLANTA BAIXA ESQUEMÁTICA - BANHEIRO

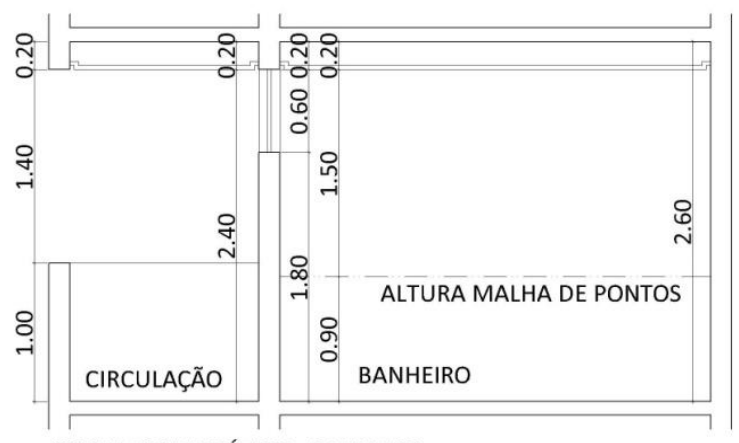

CORTE ESQUEMÁTICO - BANHEIRO
O coeficiente de transmissão luminosa adotado nas superfícies transparentes foi de 0,90. Os coeficientes de reflexão adotados nos modelos estão apresentados na Tabela 3.

\section{Caracterização do cenário urbano}

Os modelos foram inseridos em um cenário urbano definido a partir do Código de Obras, do Plano Diretor e da análise de novos loteamentos. Foi considerado um cenário urbano de ocupação máxima, com edificações de quatro pavimentos (térreo + três andares), classificada como R5 pela legislação municipal. Adotou-se uma malha de quadras de $3 \times 3$, cada quadra com 40 lotes de 10,00 $\mathrm{m}$ x 20,00 m. Foi necessário o remembramento de 4 lotes, para inserir edificações multifamiliares R5, cujos volumes edificados são 14,00 m x 30,00 m x 12,30 m (LxPxA), em função dos recuos exigidos: $3,00 \mathrm{~m}$ laterais e de fundos, e 5,00 m frontais. A rua possui duas faixas de rolamento de $5,00 \mathrm{~m} \mathrm{e}$ dois passeios de $2,00 \mathrm{~m}$. O volume do edifíciobase, onde foram inseridos os modelos analisados, está destacado na planta do cenário proposto na Figura 7. Cada ambiente está locado no centro do volume edificado. Duas alturas foram simuladas, térreo e quarto pavimento (níveis $+0,50 \mathrm{~m} \mathrm{e}+8,60$ $\mathrm{m})$, para cada orientação (norte, leste, sul e oeste).

\section{Simulação dinâmica da luz natural}

A simulação da luz natural, neste estudo, foi realizada com o software Daysim, um dos programas de simulação da iluminação natural recomendados pelo RTQ-R (BRASIL, 2010). Desenvolvido pelo National Research Council Canada (NRCC) e pelo Fraunhofer Institute for Solar Energy Systems, o software é baseado no algoritmo do Radiance para calcular as iluminâncias internas de um ambiente para o período de 1 ano em todas as condições de céu (REINHART, 2010). As variáveis definidas resultaram em 480 combinações, como mostra o esquema da Figura 8.

Foi utilizado o arquivo climático TRY da cidade estudada, que se encontra disponível para download no site do Laboratório de Eficiência Energética em Edificações da Universidade Federal de Santa Catarina (www.labeee.ufsc.br).

Cada arquivo de modelo tridimensional foi produzido com quatro ambientes - térreo e $4^{\circ}$ pavimento com duas orientações opostas (norte e sul, leste e oeste) apresentado na Figura 9.

Foi utilizado o modo padrão para os parâmetros de simulação (Radiance), recomendado para um ambiente que tenha materiais básicos (translúcidos, transparentes e opacos) e sistema de iluminação natural simples, sem cortinas ou brises. A iluminação natural foi analisada, no período de 1 ano, no horário das $6 \mathrm{~h}$ às $17 \mathrm{~h}$ de cada dia, considerando-se o uso contínuo dos espaços em análise.

As variáveis de análise da eficiência da luz natural utilizadas foram a autonomia da luz natural (ALN) e a iluminância natural útil (INU). $\mathrm{O}$ valor adotado para a ALN foi de 300 lux, recomendado pela NBR 5413 (ABNT, 1992a), para iluminação geral de áreas com tarefas visuais simples e para iluminação local em ambientes residenciais. O relatório disponibilizado pelo Daysim apresenta a INU em três faixas (INU < 100 lux, INU 100-2000 lux e INU > 2000 lux). Neste estudo adotaram-se 3.000 lux como o valor excessivo da INU, com base em Mardaljevic et al. (2011) e Mardaljevic et al. (2012). 
Tabela 3 - Coeficiente de reflexão das superfícies

\begin{tabular}{c|c}
\hline SUPERFÍCIES & CARACTERÍSTICA \\
\hline Ruas & $18 \%$ de refletância \\
Passeios, recuos e afastamentos & $27 \%$ de refletância \\
Paredes externas & $55 \%$ de refletância \\
Piso interno & $30 \%$ de refletância \\
Teto interno & $84 \%$ de refletância \\
Paredes internas & $58 \%$ de refletância \\
\hline
\end{tabular}

Fonte: Lam (1986) e Reinhart (2010).

Figura 7 - Malha urbana elaborada para simulação

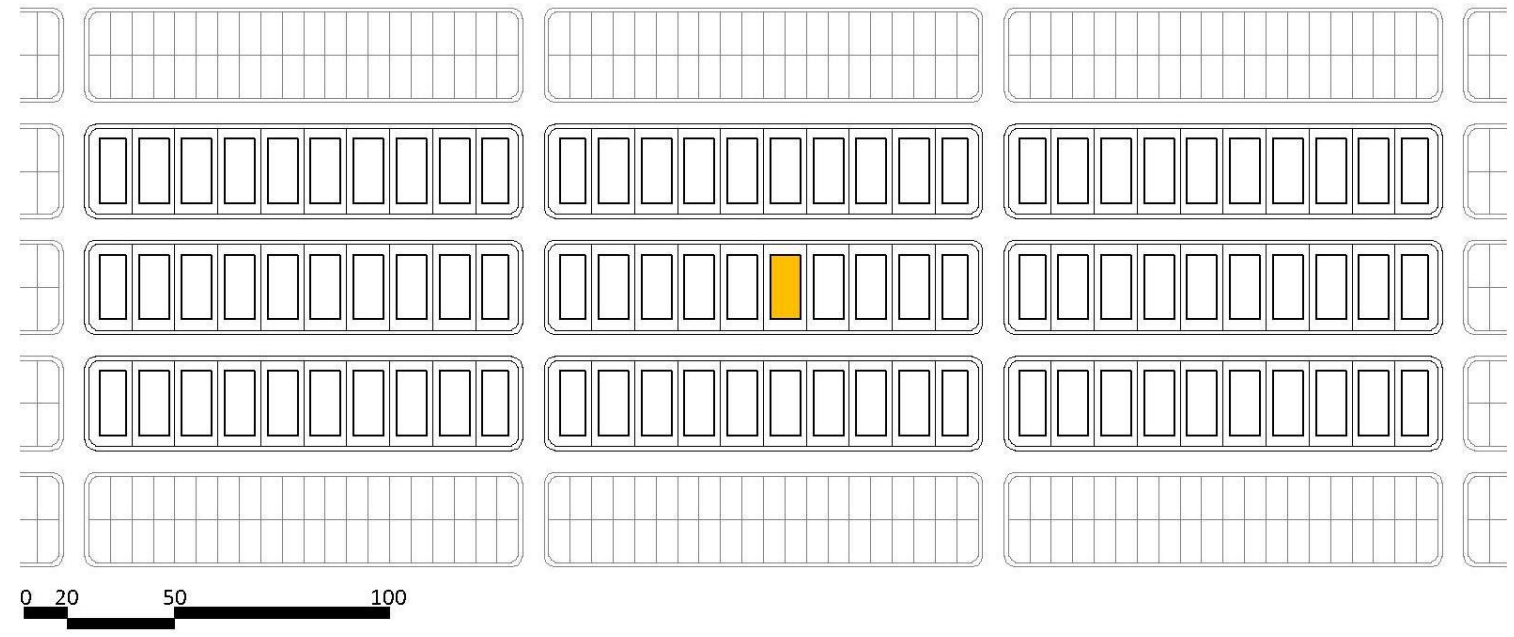

Figura 8 - Esquema metodológico de combinações

\begin{tabular}{|c|c|c|c|c|c|c|}
\hline $\begin{array}{l}\text { AMBIENTE } \\
\text { INTERNO }\end{array}$ & $\begin{array}{l}\text { COMPONENTE DE } \\
\text { CONDUÇÃO (CC) }\end{array}$ & $\begin{array}{c}\text { PEITORIL DO } \\
\text { CC }\end{array}$ & CC x EDIFÍCIO & $\begin{array}{c}\text { PROFUNDIDADE } \\
\text { DO CC }\end{array}$ & PAVIMENTO & ORIENTAÇÃO \\
\hline SALA/ QUARTO 01 & VARANDA & TRANSPARENTE & & $1,20 \mathrm{~m}$ & & \\
\hline QUARTO 02 & VARANDA & OPACO & & $1,50 \mathrm{~m}$ & & NORTE $\left(0^{\circ}\right)$ \\
\hline QTO EMPREGADO & & & SALIENTE & $200 \mathrm{~m}$ & TÉRREO & $\operatorname{LESTE}\left(90^{\circ}\right)$ \\
\hline COZINHA & CIRCULAÇÃOO & OPACO & ENCRAVADO & $2,50 \mathrm{~m}$ & $4^{\circ}$ ANDAR & $\operatorname{SUL}\left(180^{\circ}\right)$ \\
\hline BANHEIRO & & & & $3,00 \mathrm{~m}$ & & OESTE $\left(270^{\circ}\right)$ \\
\hline $1+1+3$ & {$[(1 \times 1) \times 2]+(3 \times 1)$} & $(1 \times 2)+(4 \times 1)$ & $6 \times 2$ & $12 \times 5$ & $60 \times 2$ & $120 \times 4=480$ \\
\hline
\end{tabular}

Figura 9 - Planta baixa esquemática e vista tridimensional dos modelos

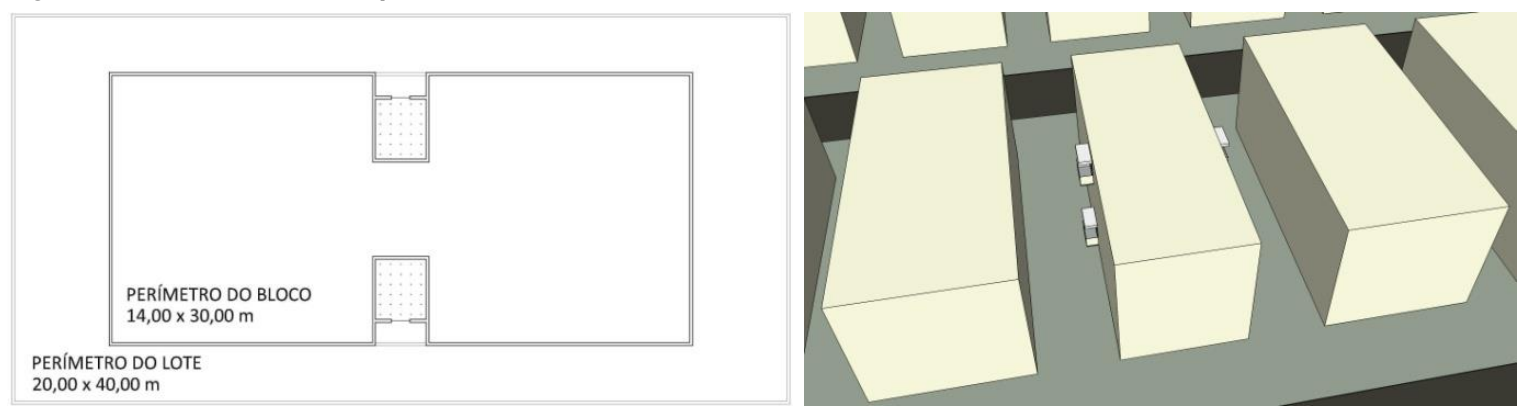




\section{Procedimentos adotados na análise dos resultados}

Os valores da ALN foram utilizados para verificar a distribuição da luz natural nos ambientes através de gráficos de curva de cores falsas (IsoALN). Esses gráficos foram produzidos no software Golden Software Surfer 9. Os valores da INU foram utilizados para verificar se os níveis de iluminância proporcionados por dimensões mínimas de aberturas com sistemas de condução da luz atendem aos valores tomados como referência.

O critério determinado para avaliar o desempenho da iluminação natural foi o seguinte: metade do ambiente deve apresentar o valor mínimo de $75 \%$ da INU no intervalo de 100-3.000 lux. Esse critério foi desenvolvido a partir da legislação neozelandesa (STEWART, 2008) e do Leadership in Energy and Environmental Design (LEED) (UNITED..., 2011), os quais indicam a manutenção de iluminâncias mínimas, considerando parâmetros dinâmicos da iluminação natural, durante $75 \%$ do período de ocupação, e também da recomendação de Lynes (1968), de atender aos valores mínimos da legislação em pelo menos metade do ambiente, e do estudo de Reinhart (2005), que considera suficiente a iluminação proporcionada por uma abertura lateral quando pelo menos metade do ambiente apresenta o valor da ALN estipulada.

Em comparação ao parâmetro proposto pelo RTQR (BRASIL, 2010) para avaliação da iluminação natural, percebe-se que o RTQ-R é um pouco mais flexível, pois a iluminância mínima é de apenas 60 lux, apesar de as demais variáveis serem similares às adotadas neste estudo:

(a) nos ambientes sem proteção solar, deve-se atender à iluminância mínima em $70 \%$ do ambiente, durante $70 \%$ das horas com luz natural no ano; e

(b) nos ambientes com proteção solar (como os modelos simulados nesta pesquisa), deve-se obter 60 lux de iluminância em 50\% do ambiente, durante $70 \%$ das horas com luz natural no ano.

A partir dos valores em porcentagem da área iluminada dos ambientes (INU 100-3.000 lux $\geq$ $75 \%$ ) para cada modelo, foram realizados testes de hipóteses para perceber quais variáveis afetam mais a disponibilidade da iluminação natural, comparando duas a duas as categorias das seguintes variáveis qualitativas (características): pavimento, tipo de varanda/circulação, tipo de peitoril, orientação e profundidade do componente de condução. Foi utilizado o teste de Mann-
Whitney, que é um procedimento alternativo (não paramétrico) ao teste $\mathrm{t}$ de Student, para comparar uma variável quantitativa entre dois grupos quando a suposição de normalidade não é satisfeita (VIEIRA, 2003). O nível de significância de 5\% foi adotado. A estatística usada como base desse teste foi, então, utilizada para construir intervalos de confiança para o valor esperado da diferença da variável quantitativa entre os grupos.

\section{Resultados}

Os itens a seguir descrevem os principais resultados obtidos neste estudo.

\section{Autonomia da Luz Natural (ALN)}

A partir da análise da ALN, identificou-se que as variáveis com maior impacto sobre a distribuição da luz natural foram a "forma" e a "posição" da abertura, e o "componente de condução saliente ou encravado". As variáveis "profundidade do componente de condução", "orientação", "transparência do peitoril" e "pavimento", apresentam maior influência nos níveis de iluminação e serão tratadas em detalhes na análise da INU. Assim, as Figuras 10 a 13 ilustram o comportamento da ALN 300 lux nos ambientes que possuem componente de condução de $1,50 \mathrm{~m}$ de profundidade, peitoril opaco e orientação sul.

A partir da Figura 10, percebe-se que a distribuição dos valores da ALN 300 lux apresenta um comportamento particular para cada ambiente analisado. As diferenças podem ser atribuídas, principalmente, à configuração das aberturas, como já havia verificado Bittencourt et al. (1995). $\mathrm{Na}$ sala, cuja abertura é uma porta, nota-se que a área central apresenta maiores valores da ALN 300 lux, reduzindo-se na direção das laterais. Também se pode perceber decréscimo gradual da ALN 300 lux à medida que se distancia da abertura. A abertura do quarto é uma janela baixa horizontal, o que favorece maior uniformidade entre o centro e as laterais do ambiente, além de um decréscimo gradual da ALN 300 lux em função da profundidade. A iluminação do quarto de empregados e da cozinha tem comportamento semelhante, uma vez que a abertura desses dois ambientes é semelhante: uma janela alta, junto ao teto, que ocupa toda a largura da parede na qual está situada; nota-se que os maiores valores da ALN 300 lux não estão próximos à janela, mas na segunda linha da malha de sensores. A distribuição dos valores da ALN 300 lux no banheiro é semelhante à distribuição percebida no quarto de empregados e na cozinha, porém com valores inferiores. 
Figura 10 - ALN - Componente de condução saliente com 1,50 m de profundidade, peitoril opaco, orientação sul e térreo

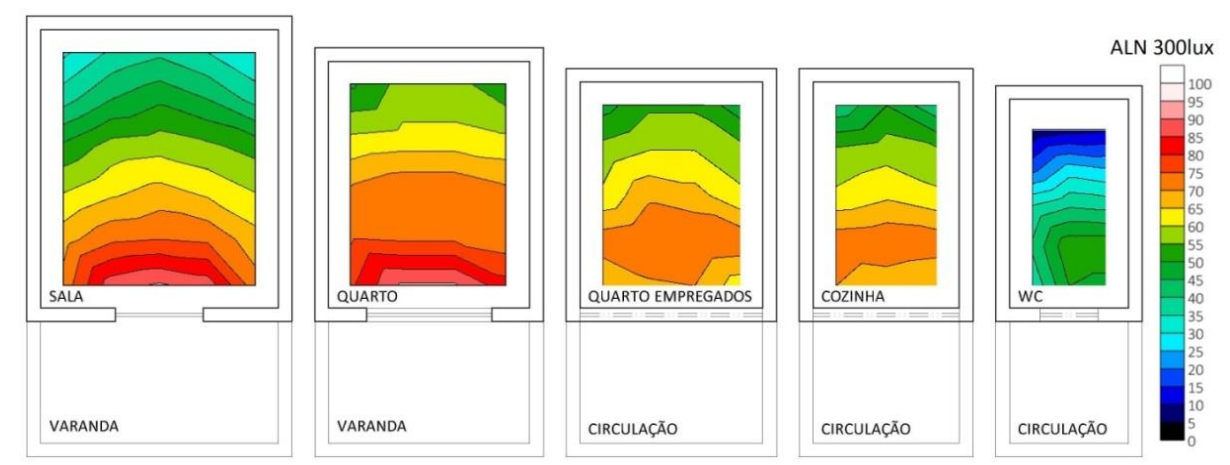

Considerando-se a recomendação de Reinhart (2005) em relação à distribuição de níveis iguais ou acima de 300 lux em pelo menos $50 \%$ da área do ambiente, pode-se concluir que esses modelos apresentam iluminação natural suficiente, à exceção do banheiro, cuja área da abertura é de apenas $1 / 8$ da área do piso, enquanto nos outros ambientes essa relação é de $1 / 4$

A Figura 11 apresenta os gráficos elaborados para os modelos com componente de condução saliente com 1,50 $\mathrm{m}$ de profundidade, peitoril opaco, orientação sul e $4^{\circ}$ pavimento. A principal diferença entre os gráficos das Figura 10 e 11 está no aumento de horas com valores iguais ou maiores que 300 lux nos ambientes do pavimento superior, que podem ser considerados iluminados naturalmente, inclusive o banheiro.

A variação do componente de condução, encravado ou saliente (Figuras 10 a 13), impacta sobretudo nos níveis de iluminação, mas também no formato das isolinhas. Nos modelos com componente de condução saliente, as curvas isolinhas são mais suaves, com raio maior, enquanto nos modelos com componente de condução encravado, os raios das curvas são menores. Além disso, as áreas laterais das aberturas apresentam valores da ALN 300 lux mais contrastantes com os valores em frente à abertura, devido à obstrução causada pelas paredes laterais dos componentes de condução. Isso fica bastante evidente nos modelos da sala e do quarto: a abertura mais estreita da sala cria uma área central mais iluminada do que as laterais; no quarto, com a abertura mais larga, a área central (mais iluminada) tem maior dimensão que na sala. Com o componente de condução encravado, o decréscimo gradual da ALN 300 lux em função da distância em relação à abertura é semelhante aos modelos com componente de condução saliente, porém mais contrastante. Os banheiros dos modelos com componente de condução encravado, independentemente das variáveis, apresentam iluminância inferior a 300 lux. O quarto, localizado no pavimento térreo, apresenta comportamento similar ao quarto de empregados e à cozinha, onde a área mais iluminada está nos sensores da segunda linha, em razão da maior obstrução da abertura neste pavimento.

A partir da análise desses gráficos, observa-se que o ambiente que apresenta maior profundidade de penetração da luz no plano de trabalho é o quarto. Essa melhor distribuição da ALN 300 lux pode ser atribuída à localização da área transparente acima do plano de análise, diferentemente da sala, que apresenta $35 \%$ da área envidraçada abaixo do plano de trabalho, bem como à maior largura da abertura e à menor profundidade do quarto - a parede de fundo serve como fonte de iluminação natural indireta a partir das reflexões internas. O quarto de empregados e a cozinha apresentam profundidade de penetração da luz semelhante à da sala, porém nos ambientes com janela alta verificase maior uniformidade na distribuição, o que evidencia as variáveis "posição" e "forma" da abertura como determinantes na distribuição da luz natural no ambiente interno, não apenas a relação entre as áreas de abertura e de piso. Nos banheiros, tendo como critério a ALN 300 lux, apenas os modelos do pavimento superior com componente de condução saliente têm iluminação natural suficiente.

\section{Iluminância Natural Útil (INU)}

Os resultados a seguir estão apresentados conforme os ambientes estudados.

Das 160 combinações da sala, 44 (27,50\%) apresentam-se inadequadas, considerando-se o critério de análise utilizado (INU 100-3.000 lux $\geq$ $75 \%$ em pelo menos $50 \%$ da área do ambiente). Os modelos que apresentam iluminação natural ineficiente encontram-se principalmente no pavimento térreo e possuem varanda encravada. As edificações do entorno e as paredes laterais do componente de condução contribuem para a redução da iluminação natural. 
Figura 11 - ALN - Componente de condução saliente com 1,50 m de profundidade, peitoril opaco, orientação sul e $4^{\circ}$ pavimento
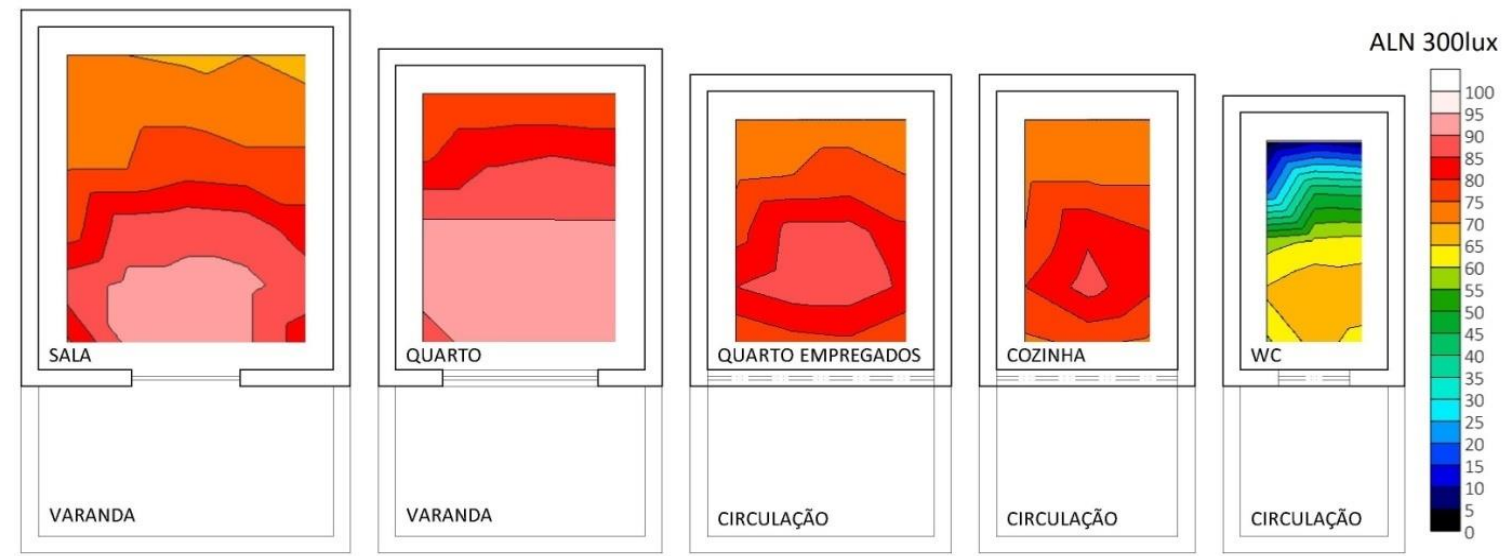

Figura 12 - ALN - Componente de condução encravado com profundidade de 1,50 m, peitoril opaco, orientação sul, térreo
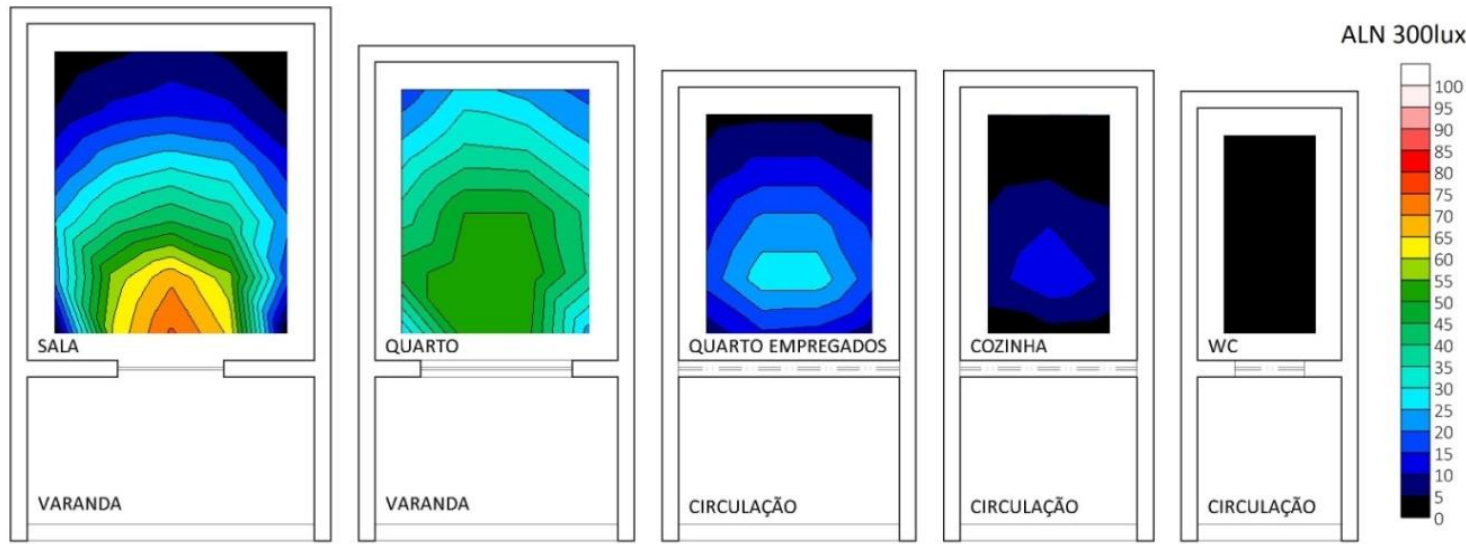

Figura 13 - ALN - Componente de condução encravado com profundidade de 1,50 m, peitoril opaco, orientação sul, $4^{\circ}$ pavimento
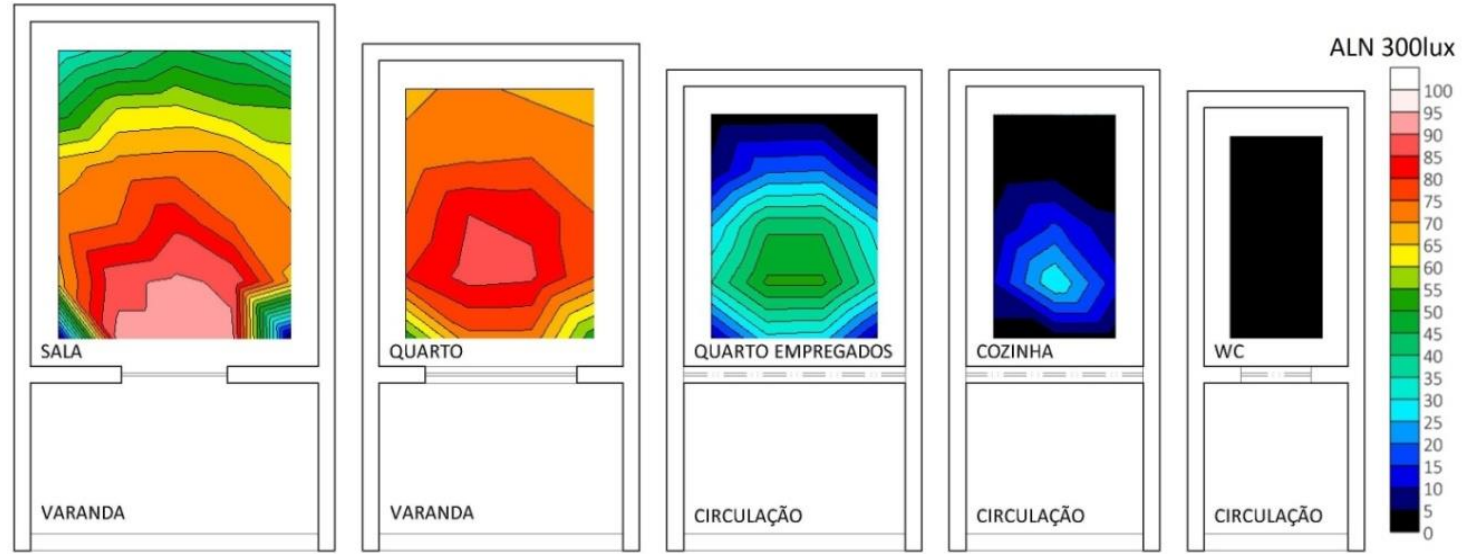

A partir do gráfico de dispersão entre a área iluminada (porcentagem da área do ambiente com INU 100-3.000 lux $\geq 75 \%$ ) e a média da área iluminada (média, em porcentagem, da INU 1003.000 lux $\geq 75 \%$ ) dos modelos da sala, apresentado na Figura 14, pode-se analisar qualitativamente os modelos. Há melhor aproveitamento da luz natural quando a varanda é saliente, com dimensão entre 2,00 m e 3,00 m, no pavimento superior e com peitoril transparente. Os modelos do pavimento 
térreo com varanda encravada de $2,00 \mathrm{~m}$ a $3,00 \mathrm{~m}$ apresentam pior desempenho. Os modelos com peitoril transparente têm médias um pouco melhores.

As variáveis analisadas geraram 80 combinações do quarto, das quais $18(22,50 \%)$ não atendem ao critério desenvolvido para INU 100-3.000 lux. Os ambientes do pavimento térreo com varanda encravada, independentemente dos critérios de profundidade e orientação, mostram-se inadequados. Os modelos com melhor aproveitamento da luz natural apresentam varanda saliente, independentemente da profundidade e da altura do pavimento, assim como os ambientes com varanda encravada entre $1,20 \mathrm{~m}$ e $2,00 \mathrm{~m}$ no pavimento superior. Os modelos com pior desempenho estão no pavimento térreo, com varanda encravada entre $2,00 \mathrm{~m}$ e $3,00 \mathrm{~m}$ de profundidade, como se percebe na Figura 15.

Figura 14 - Dispersão entre área iluminada e média da área iluminada - sala

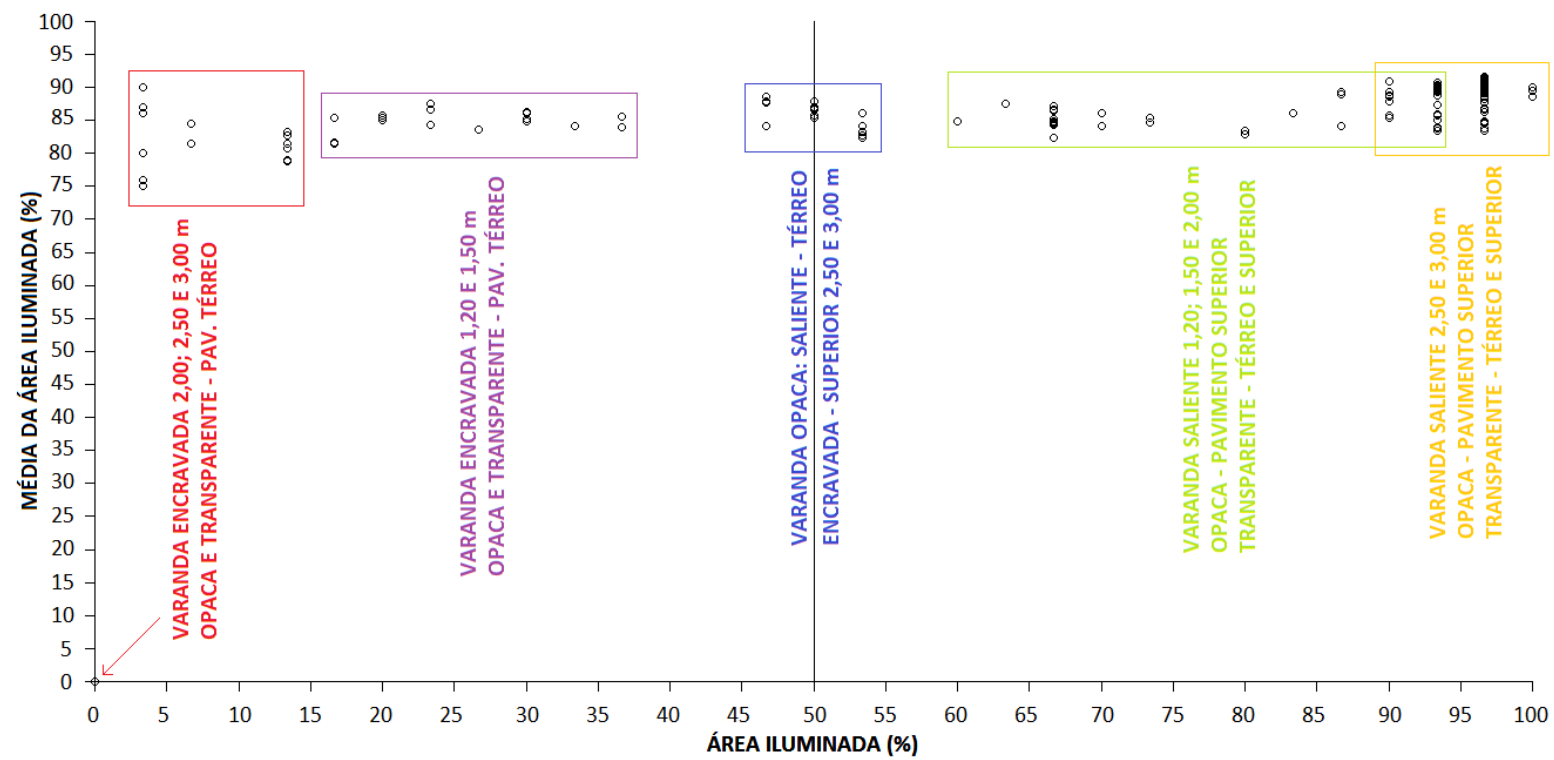

OBS.: ÁREA ILUMINADA: \% DA ÁREA DO AMBIENTE COM INU 100-3000lux $\geq 75 \%$; MÉDIA DA ÁREA ILUMINADA: MÉDIA, EM \%, DA INU 100-3000lux $\geq 75 \%$

Figura 15 - Dispersão entre área iluminada e média da área iluminada - quarto

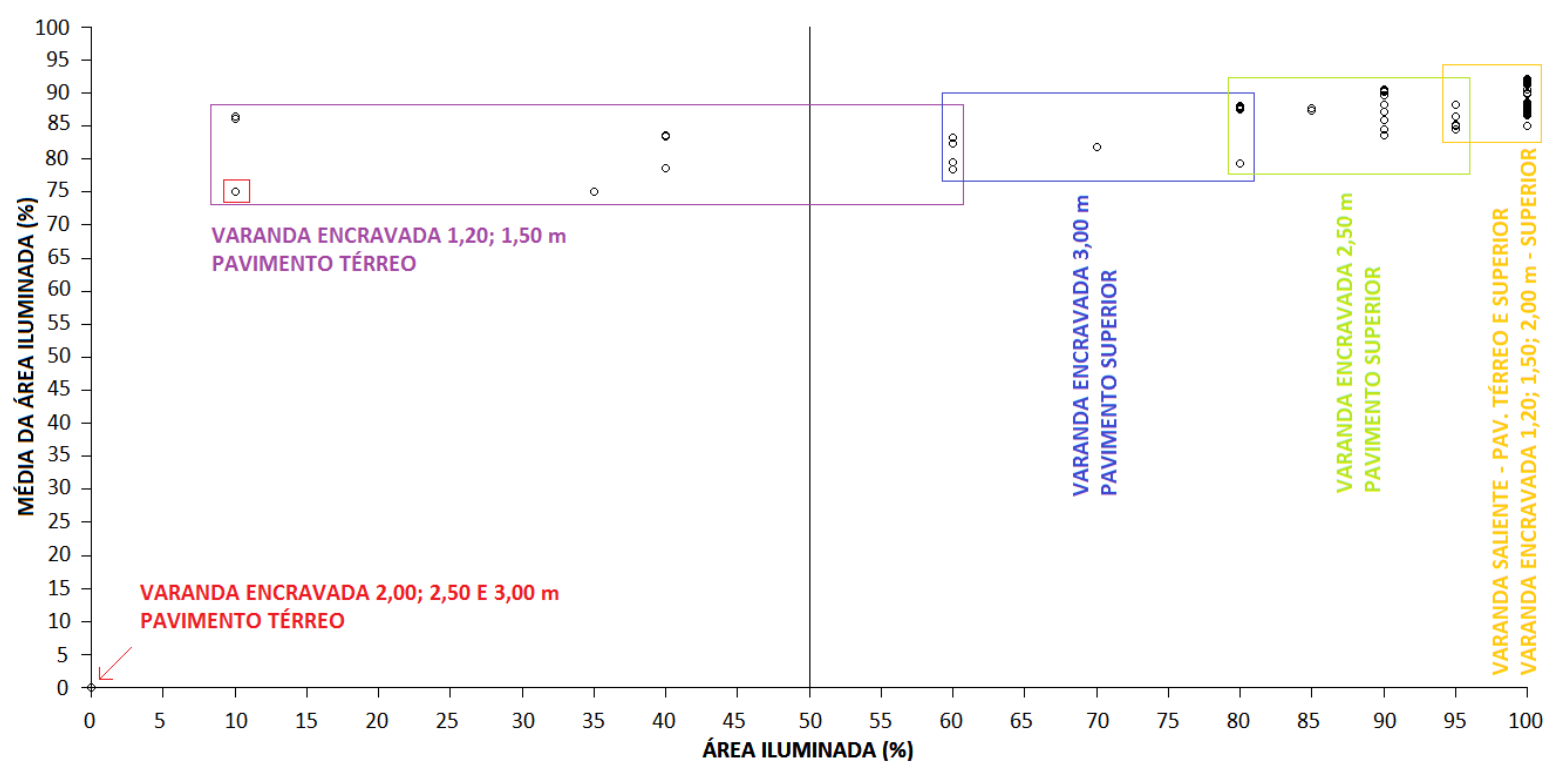

OBS.: ÁREA ILUMINADA: \% DA ÁREA DO AMBIENTE COM INU 100-3000lux $\geq 75 \%$; MÉDIA DA ÁREA ILUMINADA: MÉDIA, EM \%, DA INU 100-3000lux $\geq 75 \%$ 
O quarto de empregados tem 80 combinações das variáveis; dessas, 32 combinações $(40 \%)$ apresentam iluminação natural insuficiente. Como na sala e no quarto, os modelos de quarto de empregados com menor obstrução da abertura apresentam maiores níveis de iluminação natural, bem como maior frequência de ocorrência de níveis satisfatórios, como os modelos com circulação saliente de $2,50 \mathrm{~m}$ e $3,00 \mathrm{~m}$ de profundidade. Os modelos com pior desempenho possuem circulação encravada e profundidade entre $1,20 \mathrm{~m}$ e $2,00 \mathrm{~m}$ no térreo, e com profundidade de $2,50 \mathrm{~m}$ e $3,00 \mathrm{~m}$ no térreo e no $4^{\circ}$ pavimento (Figura 16).

Menor possibilidade de aproveitamento da iluminação natural, comparando-se com os ambientes anteriores, foi observada na cozinha (Figura 17), onde 46 modelos $(57,50 \%)$ apresentam iluminação natural insuficiente. Menor obstrução da abertura resulta em maior potencial de aproveitamento da iluminação natural, como os modelos com circulação saliente no pavimento superior. Os modelos com circulação encravada de $1,20 \mathrm{~m}$ e 1,50 m, no térreo, e de profundidade entre 2,00 $\mathrm{m}$ e 3,00 m, nos dois pavimentos, apresentam pior desempenho - nenhum sensor apresenta INU 100-3.000 lux $\geq 75 \%$. A configuração da abertura desse ambiente é a mesma da do quarto de empregados - janela alta -, sendo essa a razão da semelhança entre os resultados desses dois ambientes.

Das 80 combinações do banheiro, apenas 20 têm iluminação natural suficiente, ou seja, em $75 \%$ das combinações é necessário o acionamento do sistema de iluminação artificial para a utilização do ambiente. Assim como na cozinha, a menor parte das combinações apresenta resultado satisfatório, o que denota que o problema maior é a proporção entre área de abertura e a área de piso exigida pela legislação. Essa proporção parece estar muito aquém da ideal, principalmente se considerarmos que a configuração da abertura dos banheiros - sabendo-se que estes demandam privacidade - comumente é solucionada através de janela alta, configuração que, neste estudo, mostrou-se pouco eficiente na captação da luz natural quando associada a componentes de condução, principalmente encravados.

O gráfico da Figura 18 ilustra as seguintes observações: todos os modelos do banheiro com circulação encravada e os com circulação saliente, no pavimento térreo, independentemente da orientação, apresentam iluminação natural insuficiente, sendo esses, entre todos os modelos analisados, os que obtiveram o pior desempenho; os modelos com componente de condução saliente com profundidade de $2,50 \mathrm{~m}$ e $3,00 \mathrm{~m}$, no pavimento superior, têm melhores resultados, pois apresentam menor obstrução da abertura.

\section{Figura 16 - Dispersão entre área iluminada e média da área iluminada - quarto de empregados}

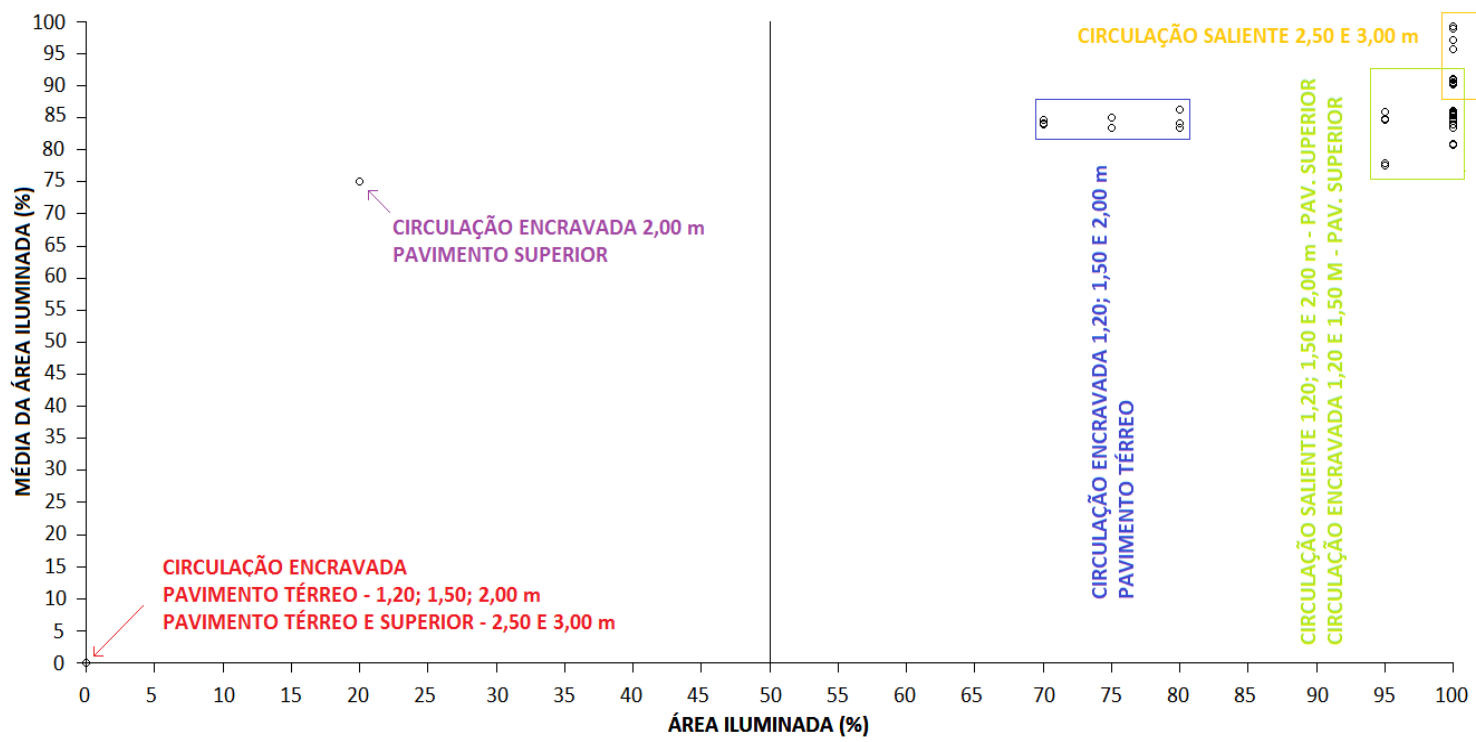

OBS.: ÁREA ILUMINADA: \% DA ÁREA DO AMBIENTE COM INU 100-3000lux $\geq 75 \%$; MÉDIA DA ÁREA ILUMINADA: MÉDIA, EM \%, DA INU 100-3000lux $\geq 75 \%$ 


\section{Figura 17 - Dispersão entre a área iluminada e a média da área iluminada - cozinha}

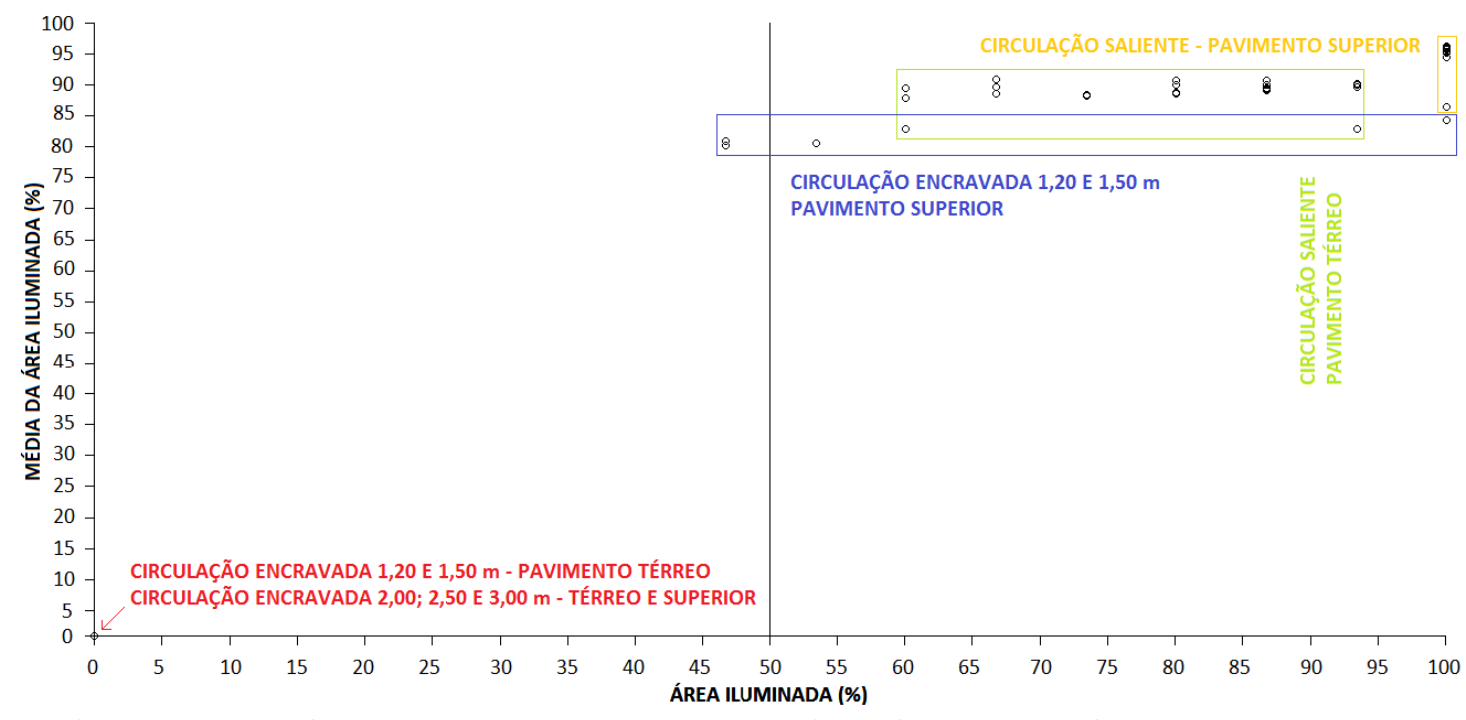

OBS.: ÁREA ILUMINADA: \% DA ÁREA DO AMBIENTE COM INU 100-3000lux $\geq 75 \%$; MÉDIA DA ÁREA ILUMINADA: MÉDIA, EM \%, DA INU 100-3000lux $\geq 75 \%$

Figura 18 - Dispersão entre área iluminada e média da área iluminada - banheiro

$100-3000$ lux $\geq 75 \%$

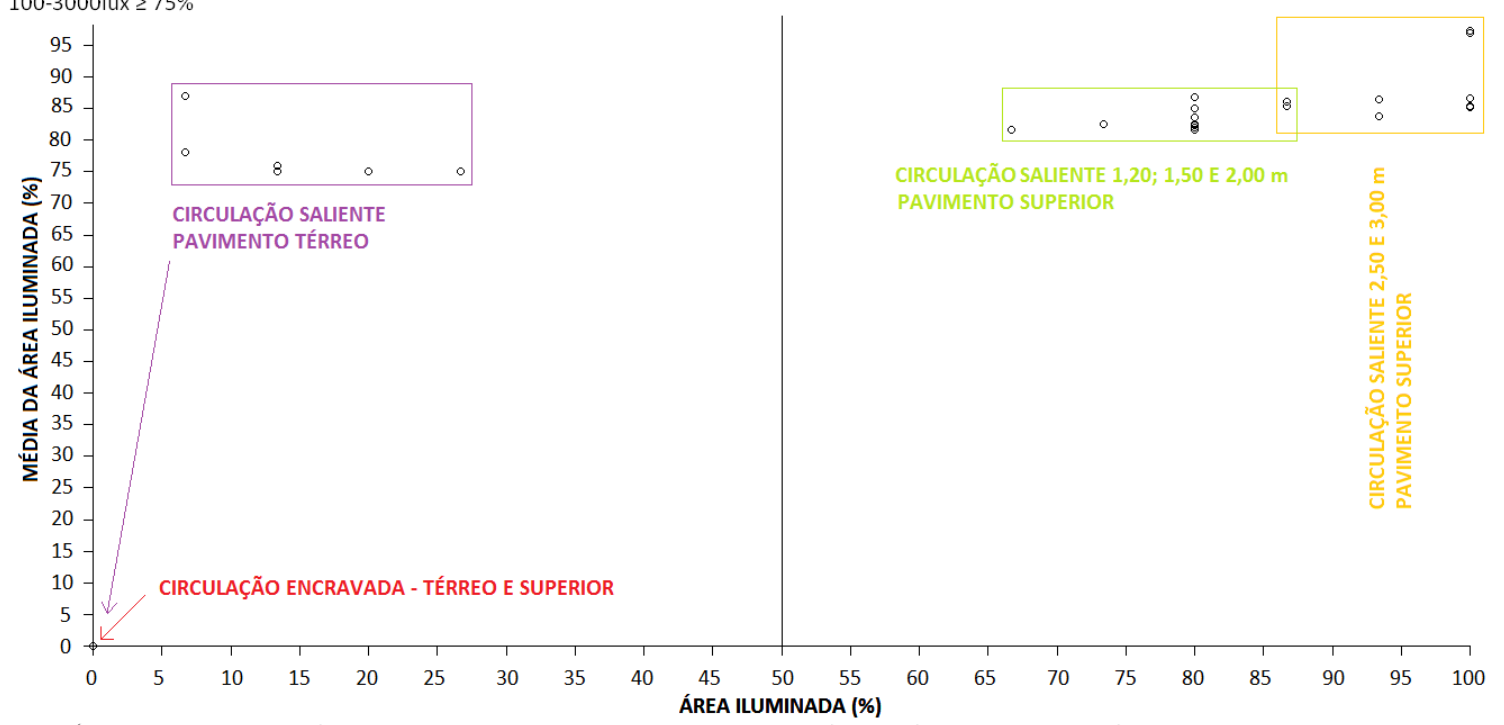

OBS.: ÁREA ILUMINADA: \% DA ÁREA DO AMBIENTE COM INU 100-3000lux $\geq 75 \%$; MÉDIA DA ÁREA ILUMINADA: MÉDIA, EM \%, DA INU 100-3000lux $\geq 75 \%$

\section{Análise comparativa entre as variáveis}

As comparações iniciais do percentual de área iluminada dos ambientes (INU 100-3.000 lux $\geq$ $75 \%$ ) estão apresentadas na Tabela 4. As variáveis que apresentam diferença significativa estão destacadas (nível de significância de 5\%).

Notou-se que a avaliação com todos os modelos de cada ambiente camufla as diferenças que podem ser percebidas ao se compararem essas mesmas combinações em dois grupos: (b) modelos com componente de condução encravado.

Assim, com os resultados dos testes de hipóteses agrupados segundo o componente de condução (encravado ou saliente), teve-se melhor percepção da influência das variáveis. As Tabelas 5 a 13 apresentam os resultados das comparações das variáveis de cada ambiente que apresentam diferenças significativas (nível de significância de $5 \%$ ).

(a) modelos com componente de condução saliente; e 
Tabela 4 - Resultado do teste de hipóteses - sala

\begin{tabular}{c|c|c|c}
\hline VARIÁVEIS & $\begin{array}{c}\text { ESTIMATIVA DA } \\
\text { DIFERENÇA }(\%)\end{array}$ & $\begin{array}{c}\text { INTERVALO DE } \\
\text { CONFIANÇA 95\% }\end{array}$ & VALOR $\boldsymbol{p}$ \\
\hline Pavimento térreo x superior & 46,67 & $36,66-59,99$ & $1,029 \times 10^{-15}$ \\
Varanda saliente x encravada & $-36,67$ & $16,66-46,67$ & $7,737 \times 10^{-09}$ \\
Peitoril opaco x transparente & 3,33 & $0,000045-16,66$ & 0,0269 \\
Norte x leste & 3,33 & $-0,000057-16,66$ & 0,1692 \\
Norte x sul & 0,0000197 & $-3,33-3,33$ & 0,5285 \\
Norte x oeste & 6,66 & $0,000015-20,00$ & 0,04618 \\
Sul x leste & 0,030 & $-13,33-3,30$ & 0,3555 \\
Leste x oeste & 0,000039 & $-6,66-10,00$ & 0,598 \\
Sul x oeste & 5,17 & $-0,000048-16,67$ & 0,09913 \\
Norte e sul x leste e oeste & $-3,33$ & $0,0000030-9,99$ & 0,03476 \\
$1,20 \mathrm{~m} \times 1,50 \mathrm{~m}$ & $-0,0000057$ & $-6,66-6,64$ & 0,9514 \\
$1,20 \mathrm{~m} \times 2,00 \mathrm{~m}$ & $-0,000019$ & $-6,66-9,99$ & 0,8548 \\
$1,20 \mathrm{~m} \times 2,50 \mathrm{~m}$ & $-0,029$ & $-3,33-19,99$ & 0,5642 \\
$1,20 \mathrm{~m} \times 3,00 \mathrm{~m}$ & $-16,66$ & $-0,029-30,00$ & 0,202 \\
$1,50 \mathrm{~m} \times 2,00 \mathrm{~m}$ & $-0,000075$ & $-3,33-6,66$ & 0,5772 \\
$1,50 \mathrm{~m} \times 2,50 \mathrm{~m}$ & $-3,32$ & $-3,32-16,66$ & 0,3621 \\
$1,50 \mathrm{~m} \times 3,00 \mathrm{~m}$ & $-16,66$ & $-6,05-30,00$ & 0,1331 \\
$2,00 \mathrm{~m} \times 2,50 \mathrm{~m}$ & $-0,0000026$ & $-3,33-10,00$ & 0,5213 \\
$2,00 \mathrm{~m} \times 3,00 \mathrm{~m}$ & $-9,99$ & $-4,99-29,99$ & 0,1604 \\
$2,50 \mathrm{~m} \times 3,00 \mathrm{~m}$ & $-3,32$ & $-3,33-29,99$ & 0,3385 \\
\hline
\end{tabular}

Tabela 5 - Teste de hipótese dos modelos com componente de condução encravado - sala

\begin{tabular}{c|c|c|c}
\hline VARIÁVEIS & $\begin{array}{c}\text { ESTIMATIVA DA } \\
\text { DIFERENÇA (\%) }\end{array}$ & $\begin{array}{c}\text { INTERVALO DE } \\
\text { CONFIANÇA 95\% }\end{array}$ & VALOR $\boldsymbol{p}$ \\
\hline Pavimento térreo x superior & 73,33 & $66,66-80,00$ & $2,464 \times 10^{-14}$ \\
Profundidade 1,20 m x 2,50 m & $-20,00$ & $3,30-46,67$ & 0,02962 \\
Profundidade 1,20 m x 3,00 m & $-30,00$ & $20,00-59,97$ & 0,006709 \\
Profundidade 1,50 m x 2,50 m & $-13,33$ & $0,000046-36,67$ & 0,02907 \\
Profundidade 1,50 m x 3,00 m & $-26,67$ & $16,66-56,67$ & 0,01618 \\
Profundidade 2,00 m x 3,00 m & $-13,34$ & $3,33-56,67$ & 0,01599 \\
\hline
\end{tabular}

Tabela 6 - Teste de hipótese dos modelos com componente de condução saliente - sala

\begin{tabular}{c|c|c|c}
\hline VARIÁVEIS & $\begin{array}{c}\text { ESTIMATIVA DA } \\
\text { DIFERENÇA (\%) }\end{array}$ & $\begin{array}{c}\text { INTERVALO DE } \\
\text { CONFIANÇA 95\% }\end{array}$ & VALOR $\boldsymbol{p}$ \\
\hline Pavimento térreo x superior & 26,67 & $20,00-29,99$ & 0,00000051 \\
Peitoril opaco x transparente & 3,33 & $0,000035-23,32$ & 0,01652 \\
Norte x leste & 3,33 & $-0,000085-23,34$ & 0,01171 \\
Norte x oeste & 9,99 & $0,000012-26,66$ & 0,002459 \\
Sul x oeste & 6,70 & $-0,000033-26,67$ & 0,01587 \\
Norte e sul x leste e oeste & $-6,67$ & $-19,99-0,000063$ & 0,0005338 \\
\hline
\end{tabular}

Tabela 7 - Teste de hipótese dos modelos com componente de condução encravado - quarto

\begin{tabular}{c|c|c|c}
\hline VARIÁVEIS & $\begin{array}{c}\text { ESTIMATIVA DA } \\
\text { DIFERENÇA (\%) }\end{array}$ & $\begin{array}{c}\text { INTERVALO DE } \\
\text { CONFIANÇA 95\% }\end{array}$ & VALOR $\boldsymbol{p}$ \\
\hline Pavimento térreo x superior & 90,00 & $60,00-90,00$ & 0,000000045 \\
\hline
\end{tabular}


Tabela 8 - Teste de hipótese dos modelos com componente de condução saliente - quarto

\begin{tabular}{c|c|c|c}
\hline \multirow{2}{*}{ VARIÁVEIS } & $\begin{array}{c}\text { ESTIMATIVA DA } \\
\text { DIFERENÇA (\%) }\end{array}$ & $\begin{array}{c}\text { INTERVALO DE } \\
\text { CONFIANÇA 95\% }\end{array}$ & VALOR $\boldsymbol{p}$ \\
\hline Norte $x$ leste & 5,00 & $0-15,00$ & 0,005886 \\
Norte $x$ sul & 7,50 & $5,00-10,00$ & 0,00047 \\
\hline
\end{tabular}

Tabela 9 - Teste de hipótese dos modelos com componente de condução encravado - quarto de empregados

\begin{tabular}{c|c|c|c}
\hline VARIÁVEIS & $\begin{array}{c}\text { ESTIMATIVA DA } \\
\text { DIFERENÇA (\%) }\end{array}$ & $\begin{array}{c}\text { INTERVALO DE } \\
\text { CONFIANÇA 95\% }\end{array}$ & VALOR $\boldsymbol{p}$ \\
\hline Pavimento térreo $\times$ superior & 20,00 & $0,000052-95,00$ & 0,000063 \\
$1,20 \mathrm{~m} \times 2,50 \mathrm{~m}$ & 50,00 & $0-100,00$ & 0,0303 \\
$1,20 \mathrm{~m} \times 3,00 \mathrm{~m}$ & 50,00 & $0-100,00$ & 0,0303 \\
$1,50 \mathrm{~m} \times 2,50 \mathrm{~m}$ & 43,05 & $0-100,00$ & 0,03204 \\
$1,50 \mathrm{~m} \times 3,00 \mathrm{~m}$ & 43,05 & $0-100,00$ & 0,03204 \\
$2,00 \mathrm{~m} \times 2,50 \mathrm{~m}$ & 10,00 & $0-20,00$ & 0,0303 \\
$2,00 \mathrm{~m} \times 3,00 \mathrm{~m}$ & 10,00 & $0-20,00$ & 0,0303 \\
\hline
\end{tabular}

Tabela 10 - Teste de hipótese dos modelos com componente de condução saliente - quarto de empregados

\begin{tabular}{c|c|c|c}
\hline VARIÁVEIS & $\begin{array}{c}\text { ESTIMATIVA DA } \\
\text { DIFERENÇA }(\%)\end{array}$ & $\begin{array}{c}\text { INTERVALO DE } \\
\text { CONFIANÇA 95\% }\end{array}$ & VALOR $\boldsymbol{p}$ \\
\hline Pavimento térreo x superior & 5,00 & $20,00-0,000057$ & 0,000065 \\
\hline
\end{tabular}

Tabela 11 - Teste de hipótese dos modelos com componente de condução encravado - cozinha

\begin{tabular}{c|c|c|c}
\hline \multirow{2}{*}{ VARIÁVEIS } & $\begin{array}{c}\text { ESTIMATIVA DA } \\
\text { DIFERENÇA (\%) }\end{array}$ & $\begin{array}{c}\text { INTERVALO DE } \\
\text { CONFIANÇA 95\% }\end{array}$ & VALOR $\boldsymbol{p}$ \\
\hline $1,20 \mathrm{~m} \times 2,00 \mathrm{~m}$ & 43,04 & $0-100,00$ & 0,03225 \\
$1,20 \mathrm{~m} \times 2,50 \mathrm{~m}$ & 43,04 & $0-100,00$ & 0,03225 \\
$1,20 \mathrm{~m} \times 3,00 \mathrm{~m}$ & 43,04 & $0-100,00$ & 0,03225 \\
$1,50 \mathrm{~m} \times 2,00 \mathrm{~m}$ & 24,18 & $0-53,34$ & 0,03225 \\
$1,50 \mathrm{~m} \times 2,50 \mathrm{~m}$ & 24,18 & $0-53,34$ & 0,03225 \\
$1,50 \mathrm{~m} \times 3,00 \mathrm{~m}$ & 24,18 & $0-53,34$ & 0,03225 \\
\hline
\end{tabular}

Tabela 12 - Teste de hipótese dos modelos com componente de condução saliente - cozinha

\begin{tabular}{c|c|c|c}
\hline VARIÁVEIS & $\begin{array}{c}\text { ESTIMATIVA DA } \\
\text { DIFERENÇA }(\%)\end{array}$ & $\begin{array}{c}\text { INTERVALO DE } \\
\text { CONFIANÇA 95\% }\end{array}$ & VALOR $\boldsymbol{p}$ \\
\hline Pavimento térreo x superior & 20,00 & $13,33-26,66$ & 0,0000000073 \\
\hline
\end{tabular}

Tabela 13 - Teste de hipótese dos modelos com componente de condução saliente - banheiro

\begin{tabular}{c|c|c|c}
\hline VARIÁVEIS & $\begin{array}{c}\text { ESTIMATIVA DA } \\
\text { DIFERENÇA }(\%)\end{array}$ & $\begin{array}{c}\text { INTERVALO DE } \\
\text { CONFIANÇA 95\% }\end{array}$ & VALOR $\boldsymbol{p}$ \\
\hline Pavimento térreo x superior & 80,00 & $80,00-86,67$ & 0,00000033 \\
\hline
\end{tabular}

\section{Análise dos resultados}

A partir da análise dos resultados, pôde-se perceber que as variáveis selecionadas neste estudo não são, isoladamente, a explicação de todas as observações descritas, porém a associação de algumas delas merece destaque.
A variável relação entre o componente de condução e o volume do edifício (varanda/ circulação saliente ou encravada) foi a que se mostrou mais significativa. $O$ modelo saliente apresenta recuo entre os edifícios, variando em função da profundidade do componente de condução, pois, de acordo com a legislação local, o afastamento entre as edificações é considerado

40 Castro, G. N. de; Leder, S. M.; Silva, L. B. da; Souza, E. L. de 
entre as faces externas dos blocos. Com isso, os componentes salientes apresentam condições mais favoráveis em relação à obstrução proveniente do entorno. Tendo em conta o critério adotado, $90,41 \%$ dos modelos com varanda/circulação saliente apresentaram iluminação natural suficiente, enquanto apenas $31,25 \%$ dos modelos com varanda/circulação encravada proporcionaram iluminação natural satisfatória.

A variável transparência do peitoril, analisada na sala, apresentou influência nos modelos com varanda saliente, propiciando melhor aproveitamento da luz natural em todos os modelos. Essa variável, contudo, nos modelos com varanda encravada não resultou em diferenças significativas no desempenho da iluminação natural. $\mathrm{O}$ impacto do peitoril transparente nos níveis de iluminação só é relevante quando a abertura é uma porta (caso da sala).

Em relação à profundidade do componente de condução, foi possível verificar diferenças entre algumas categorias, especialmente em alguns ambientes: na sala, as profundidades de $1,20 \mathrm{~m} \mathrm{e}$ $1,50 \mathrm{~m}$ tiveram desempenho similar, assim como as de $2,00 \mathrm{~m}$ a $3,00 \mathrm{~m}$ também apresentaram comportamento semelhante. Esses dois grupos apresentam diferença estimada de aproximadamente 20 pontos percentuais. No quarto de empregados e na cozinha, é observado o mesmo agrupamento, sendo a diferença mais acentuada, cerca de 30 pontos percentuais.

A altura do pavimento, considerados os pavimentos analisados neste estudo - térreo e o $4^{\circ}$ pavimento - implica diferenças significativas na iluminação dos ambientes. O pavimento superior tem maiores níveis de iluminação. $\mathrm{Na}$ sala, é estimada diferença de 46,67 pontos percentuais; no quarto, no quarto de empregados e na cozinha, 20 pontos percentuais; e no banheiro, 39,10 pontos percentuais. No térreo, à exceção do banheiro, os ambientes são suficientemente iluminados quando o componente de condução é saliente, independentemente das outras variáveis. Contudo, não há iluminação natural suficiente nos modelos com componente de condução encravado. No pavimento superior, os modelos com varanda/ circulação saliente são iluminados naturalmente, enquanto os modelos com varanda/circulação encravada de $2,00 \mathrm{~m}$ a $3,00 \mathrm{~m}$ apresentam iluminação natural insuficiente.

Em relação às demais variáveis analisadas, a orientação apresenta diferenças pouco significativas. Na sala, a variação da iluminação natural em função da orientação pode ser agregada em dois grupos: orientações norte e sul; e orientações leste e oeste. No quarto, quando considerados apenas os modelos com varanda saliente, verifica-se diferença entre a orientação norte e sul (estimada em 7,5 pontos percentuais) e norte e leste (estimada em 5,0 pontos percentuais). Nos demais ambientes, não há diferença significativa em função da orientação da abertura, provavelmente devido ao sombreamento da abertura, gerado pelo edifício vizinho ou pela varanda.

\section{Conclusões}

Os principais critérios adotados para a definição do sistema de iluminação natural nos Códigos de Obras nacionais são a proporção entre a área de piso e a área da abertura, a profundidade máxima dos ambientes, a profundidade do componente de condução (varanda e circulação) e o pé-direito. Esses critérios, em grande parte, quando adotados nos limites mínimos, não possibilitam o aproveitamento adequado da iluminação natural principalmente nos ambientes com janelas altas e componentes de condução.

A partir da análise dos resultados obtidos com este estudo sugere-se que os seguintes itens sejam alterados e/ou inseridos nos Códigos de Obras:

(a) definição de uma área transparente mínima para a abertura, independentemente da relação entre as áreas de abertura e de piso ou aumento da área de 1/8 para um valor maior. A definição da área da abertura em relação à área do piso mostrou-se inadequada ao aproveitamento da iluminação natural, principalmente nas situações de ambientes com área reduzida;

(b) definição da geometria mínima da área transparente da abertura (altura, largura e peitoril). Observou-se, neste estudo, que a abertura da sala, definida em função da área mínima e da necessidade de utilização dela como passagem para o ambiente interno, resultou em uma abertura de geometria não favorável à distribuição da luz no ambiente interno;

(c) para os casos nos quais o sistema de iluminação natural compreende componente de condução, as recomendações em relação à área de abertura e, principalmente, à geometria e à posição da abertura devem ser específicas. Aberturas altas em sistemas de condução apresentaram o pior desempenho de iluminação natural neste estudo, o que sugere que estas deveriam ser significativamente maiores, principalmente quando o sistema de condução é do tipo encravado;

(d) o limite de profundidade do componente de condução deve estar vinculado à altura do pavimento e à obstrução do entorno, segundo a ocupação máxima permitida pela legislação. Nos 
casos em análise, os componentes de condução salientes resultaram em uma condição de entorno menos obstruída, que, somada à contribuição da luz natural proveniente das laterais (no caso do componente encravado, as laterais estão fechadas), resultou em melhor desempenho; $\mathrm{e}$

(e) as dimensões mínimas da abertura do componente de condução também devem ser objeto de definição. Observou-se neste estudo que os tipos encravados e salientes apresentam diferenças significativas nos níveis de iluminação internos, assim como a transparência do peitoril apresentou influência expressiva em alguns casos.

Em relação às demais variáveis analisadas neste trabalho, a orientação apresenta diferenças pouco significativas. Apesar de os Códigos de Obras não abordarem essa variável, caso esta seja inserida, nos locais de clima similar ao deste estudo, a orientação pode ser agrupada em: norte e sul; e leste e oeste.

Os Códigos de Obras não fazem menção à transmissividade do material empregado no fechamento. Apenas o vão da abertura é determinado, pouco importando se o fechamento é transparente, translúcido ou opaco. Para climas quentes e úmidos, a caracterização adequada da abertura para ventilação (fechamento opaco) e da abertura para iluminação (fechamento transparente ou translúcido) é uma questão imperativa, o que inclui exigências específicas para cada uma delas.

Considerando-se os resultados obtidos neste trabalho, sugere-se a revisão dos Códigos de Obras em relação às regras que definem as condições de iluminação natural em edificações de uso residencial. Recomendações ou regras em relação à área mínima e geometria da abertura (altura, largura, peitoril), bem como o posicionamento dela e a transparência do fechamento, devem ser definidas de acordo com as condições climáticas do local e a disponibilidade de luz natural. Por exemplo, para locais de clima quente e úmido, o tratamento diferenciado para o fechamento da abertura (opaco, translúcido ou transparente) é uma forma de separar e destacar duas importantes funções das aberturas: ventilação e iluminação naturais.

Como principais limitações deste trabalho destacam-se algumas simplificações (para reduzir o número de modelos), como a adoção de apenas um tipo de edificação e de entorno, e a localização das aberturas no centro da parede e somente um local (clima). Trabalhos futuros devem ampliar esta análise para outros climas e variáveis da edificação e do entorno que influenciam na iluminação natural, como, por exemplo, o coeficiente de reflexão do entorno. Também se ressalta que este estudo teve como objetivo identificar a eficiência dos parâmetros utilizados em um Código de Obras, limitando-se a responder a essa questão. Estudos posteriores podem propor soluções e parâmetros mais adequados.

\section{Referências}

ALBUQUERQUE, M. S. C.; AMORIM, C. N. D. Iluminação Natural: indicações de profundidadelimite de ambientes para iluminação natural no Regulamento Técnico da Qualidade do Nível de Eficiência Energética de Edifícios Residenciais RTQ-R. Ambiente Construído, Porto Alegre, v. 12, n. 2, p. 37,57, 2012.

AMARAL, M. G. V.; PEREIRA, F. O. R. Iluminação natural: revisão da legislação construtiva de Florianópolis. In: ENCONTRO NACIONAL, 5.; ENCONTRO LATINOAMERICANO DE CONFORTO NO AMBIENTE CONSTRUÍDO, 2., Fortaleza, 1999. Anais... Fortaleza, 1999.

\section{ASSOCIAÇÃO BRASILEIRA DE NORMAS}

TÉCNICAS. NBR 12286: roteiro para elaboração e apresentação do Código de obras. Rio de Janeiro, $1992 \mathrm{~b}$.

\section{ASSOCIAÇÃO BRASILEIRA DE NORMAS} TÉCNICAS. NBR 15215-1: iluminação natural: parte 1: conceitos básicos e definições. Rio de Janeiro, 2005a.

\section{ASSOCIAÇÃO BRASILEIRA DE NORMAS} TÉCNICAS. NBR 15215-4: iluminação natural: parte 4: verificação experimental das condições de iluminação interna de edificações: método de medição. Rio de Janeiro, 2005b.

\section{ASSOCIAÇÃO BRASILEIRA DE NORMAS}

TÉCNICAS. NBR 15220-3: desempenho térmico de edificações: parte 3: zoneamento bioclimático brasileiro e diretrizes construtivas para habitações unifamiliares de interesse social. Rio de Janeiro, 2005c.

\section{ASSOCIAÇÃO BRASILEIRA DE NORMAS}

TÉCNICAS. NBR 5413: Iluminância de interiores. Rio de Janeiro, 1992a.

BAHIA, S. R. et al. Modelo Para Elaboração de Códigos de Obras e Edificações. Rio de Janeiro: IBAM/DUMA, 1997. Guia Técnico.

BAKER, N.; FANCHIOTTI, A.; STEEMERS, K. Daylighting in Architecture: a european reference book. Londres: James \& James Pulishers, 1993. 
BITTENCOURT, L. et al. Influência da Localização, Dimensão e Forma das Janelas nos Níveis de Iluminação Natural Produzidos Por Céus Encobertos. In: ENCONTRO NACIONAL, 3.; ENCONTRO LATINO-AMERICANO DE CONFORTO NO AMBIENTE CONSTRUÍDO, Gramado, 1995. Anais... Gramado, 1995.

BOUBEKRI, M. A Overview of the Current State of Daylight Legislation. Journal of the HumanEnvironment System, v. 7, n. 2, p. 57-63, 2004.

BOYCE, P. R. Why Daylight? In: INTERNATIONAL DAYLIGHTING CONFERENCE, Ottawa, 1998. Proceedings... Ottawa, 1998.

BRASIL. Portaria no 372, de 17 de setembro de 2010, que regulamento Técnico da Qualidade para o Nível de Eficiência Energética Edificações Residenciais. Rio de Janeiro, 2010. Disponível em: <http://www.inmetro.gov.br/legislacao/rtac/pdf/RT AC001599.pdf>. Acesso em: 10 abr. 2015.

CAPELUTO, I. G. The Influence of the Urban Environment on the Availability of Daylighting in Office Buildings in Israel. Building and

Environment, v. 38, n. 5, p. 745-752, may 2002.

CURITIBA. Decreto no 212/2007 de 29 de março de 2007, que aprova o regulamento de edificações do município de Curitiba e dá outras providências. Diário Oficial do Município, Curitiba, 29 de março de 2007.

FERNANDES, J. T. Código de Obras e

Edificações do DF: inserção de conceitos bioclimáticos, conforto térmico e eficiência energética. Brasília, 2009. Dissertação (Mestrado em Engenharia Civil) - Escola de Engenharia, Universidade de Brasília, Brasília, 2009.

FROTA, A. B.; SCHIFFER, S. R. Manual de Conforto Térmico. 5. ed. São Paulo: Studio Nobel, 2001.

HOPKINSON, R. G.; PETHERBRIDGE, P.; LONGMORE, J. Iluminação Natural. 2 ed. Lisboa: Fundação Calouste Gulbenkian, 1975.

JOÃO PESSOA. Lei n ${ }^{\circ} 1.347$, de 27 de abril de 1971, que institui o código de obras do município de João Pessoa. Diário Oficial de João Pessoa, 28 de abril de 1971.

JULIAN, W. G. Daylighting Standards, Codes and Policies. In: INTERNATIONAL DAYLIGHTING CONFERENCE, Ottawa, 1998. Proceedings... Ottawa, 1998.

LAM, W. M. C. Sunlighting as Formgiver For Architecture. Nova Iorque: Van Nostrand Reinhold, 1986.
LESLIE, R. P. Capturing the Daylight Dividend in Buildings: why and how? Building and Environment, v. 38, p. 381-385, 2003.

LYNES, J. A. Principles of Natural Lighting. Londres: Elsevier, 1968.

MACEIÓ. Lei n ${ }^{\circ} 5593$, de 08 de fevereiro de 2007 , que institui o código de urbanismo e edificações do município de Maceió, estabelece o zoneamento da cidade de acordo com os parâmetros de macrozoneamento do plano diretor de desenvolvimento urbano (lei no 5486/05) e dá outras providências. Diário Oficial do Município, Maceió, 09 de fevereiro de 2007.

MARAGnO, G. V. Sombras Profundas: dimensión estética y repercusión ambiental del diseño de la varanda en la arquitectura brasileña. Barcelona, 2010. Tese (Doutorado em Engenharia Civil) - Escola de Engenharia, Universitat Politécnica de Catalunya, Barcelona, 2010.

MARDALJEVIC, J. et al. Daylighting Metrics For Residential Buildings. In: CIE, 27., Sun City, África do Sul, 2011. Proceedings... Sun City, 2011.

MARDALJEVIC, J. et al. Daylighting Metrics: is there a relation between useful daylight illuminance and daylight glare probability? In: BUILDING SIMULATION AND OPTIMIZATION CONFERENCE BSO12. Loughborough, 2012. Proceedings... Loughborough, 2012.

MARDALJEVIC, J.; REINHART, C. F.; ROGERS, Z. Dynamic Daylight Performance Metrics For Sustainable Building Design. Leukos, v. 3, n. 1, 2006.

\section{MASCARÓ, J. L. O Custo das Decisões}

Arquitetônicas. 3. ed. Porto Alegre: JLM, 2004.

MATOS, M. et al. Análise de Diferentes Métodos de Avaliação do Aproveitamento da Luz Natural. In: ENCONTRO NACIONAL E V ENCONTRO LATINO-AMERICANO DE CONFORTO NO AMBIENTE CONSTRUÍDO, 9., Ouro Preto, 2007. Anais... Ouro Preto, 2007.

NATAL. Lei complementar $n^{\circ} 55$, de 27 de janeiro de 2004, que institui o código de obras e edificações do município de Natal e dá outras providências. Diário Oficial do Município, Natal, 29 de janeiro de 2004.

PEREIRA, F. O. R. Curso de Iluminação Natural no Ambiente Construído. In: ENCONTRO NACIONAL DE CONFORTO NO AMBIENTE CONSTRUÍDO, 3., Gramado, 1995. Anais... Gramado, 2011. 
PORTO VELHO. Lei $\mathrm{n}^{\circ}$ 63, de 13 de abril de 1973, que estabelece normativas para as edificações em geral e dá outras providências. Diário Oficial do Município, Porto Velho, 14 de abril de 1973.

RECIFE. Lei $\mathrm{n}^{\circ}$ 16.292, de 26 de janeiro de 1997 , que regula as atividades de edificações e instalações, no município do Recife, e dá outras providências. Diário Oficial do Município, Recife, 28 de janeiro de 1997.

REINHART, C. F. Simulation-Based Review of the Ubiquitous Window-Headheight to Daylit Zone Depth Rule-of-Thumb. In: BUILDINGS SIMULATION, Toronto, 2005. Proceedings... Toronto, 2005.

REINHART, C. F. Tutorial on the Use of Daysim Simulations For Sustainable Design. Cambridge, Havard University, 2010. Tutorial.

REINHART, C. F.; WEISSMAN, D. A. The Daylit Area: correlating architectural student assessments with current and emerging daylight availability metrics. Building and Environment, v. 50, p. 155-162, 2012.

SERRA, R. Daylighting: renewable and Sustainable Energy Reviews, v. 2, n. 1/2, 1998.
STEWART, K. New Zealand Building Code Clause G7 Compliance Assessment Tool: development and implementation. Victoria, 2008. Dissertação (Mestrado em Engenharia Civil) Wellington, Victoria University of Wellington, 2008.

\section{THE CHARTERED INSTITUTION OF} BUILDING SERVICES ENGINEERS. Windows Design: applications manual. Londres, 1987.

UNITED STATES GREEN BUILDING COUNCIL. LEED 2009 For New Construction and Major Renovations Rating System With Alternative Compliance Paths For Projects Outside the United States. Washington, 2011.

VIEIRA, S. Bioestatística: tópicos avançados. Rio de Janeiro: Campus, 2003.

\section{Agradecimentos}

Agradecimentos à Coordenação de Aperfeiçoamento de Pessoal de Nível Superior (Capes), pelo auxílio financeiro na forma de bolsa de estudo, e ao Laboratório de Métodos Quantitativos Aplicados - LabMEQA, DEP/CT/UFPB, pelo auxílio na análise estatística.

Guilherme Nóbrega de Castro

Laboratório de Conforto Ambiental, Universidade Federal da Paraíba | Campus Universitário I, Castelo Branco | João Pessoa -PB - Brasil | CEP 58051-900 | Tel.: (31) 8336-9798 | E-mail: gnobrega.arq@gmail.com

Solange Maria Leder

Laboratório de Conforto Ambiental, Departamento de Arquitetura | Universidade Federal da Paraíba | Tel.: (83) 3216-7179 |

E-mail: solangeleder@yahoo.com.br

\section{Luiz Bueno da Silva}

Laboratório de Métodos Quantitativos Aplicados, Departamento de Engenharia de Produção | Universidade Federal da Paraíba | Tel.: (83) 3216-7549 | E-mail: silvalb@superig.com.br

\section{Erivaldo Lopes de Souza}

Laboratório de Métodos Quantitativos Aplicados, Departamento de Engenharia de Produção | Universidade Federal da Paraíba | Tel.: (83) 3216-7549 | E-mail: elopesouza@hotmail.com

\section{Revista Ambiente Construído}

Associação Nacional de Tecnologia do Ambiente Construído

Av. Osvaldo Aranha, $99-3^{\circ}$ andar, Centro

Porto Alegre - RS - Brasil

$$
\text { CEP } 90035-190
$$

Telefone: +55 (51) 3308-4084

Fax: +55 (51) 3308-4054

www.seer.ufrgs.br/ambienteconstruido

E-mail: ambienteconstruido@ufrgs.br 